\title{
TRANSICIÓN A LOS ORGANISMOS ACREDITADOS PARA LA ADOPCIÓN INTERNACIONAL* TRANSITION TO CREDITED ORGANISMS FOR INTERNATIONAL ADOPTION
}

\author{
Paula VÁzQuez Colomo** \\ Graduada en Derecho y Graduada en Administración y Dirección de Empresas \\ Universidad Carlos III de Madrid
}

Recibido: 13.07.2016 / Aceptado: 29.07.2016

DOI: http://dx.doi.org/10.20318/cdt.2016.3267

Resumen: La introducción de los Organismos Acreditados para la Adopción Internacional en el proceso de adopción internacional supone la introducción de una vía de tramitación privada que contrasta con la anterior tramitación exclusivamente pública del proceso de adopción internacional. Tal introducción ha dado lugar a una amplia regulación de tales organismos con el objetivo de regular y controlar su funcionamiento. Este estudio realiza un breve análisis sobre la institución jurídica de la adopción internacional en España, centrándose en la intervención de los Organismos Acreditados para la Adopción Internacional en el procedimiento de adopción internacional, así como en el estudio de la regulación de tales organismos.

Palabras clave: adopción internacional, Organismo Acreditado para la Adopción Internacional, fase administrativa de instrucción.

Abstract: The introduction of the Credited Organisms for International Adoption in the international adoption process involves the introduction of a way of private transaction that differs with the previous transaction of international adoption that was exclusively public. As a result the introduction resulted in a broad regulation of those organisms with the objective of regulate and control its performance. This study provides a brief analysis of the legal institution of international adoption in Spain, as well as of the involvement of Credited Organisms for International Adoption in the international adoption process and the research of the regulation of such Organisms.

Keywords: international adoption, Credited Organism for International Adoption, administrative phase of instruction.

Sumario: I. Introducción. II. La adopción internacional en Derecho Internacional Privado Español. 1. Breve referencia a las vías de constitución de adopciones internacionales en España con especificación de las tareas delegadas a los Organismos Acreditados para la Adopción Internacional. A) Adopción Internacional constituida ante Autoridad Española. a) Fase Administrativa de Instrucción. b) Fase Judicial de Constitución. B) Adopción Internacional constituida ante Autoridad Extranjera. 2. El proceso post-adoptivo. III. La intervención de los Organismos Acreditados para la

\footnotetext{
* Extracto del Trabajo de Fin de Grado para la obtención del Grado en Derecho y el Grado en Administración y Dirección de Empresas por la Universidad Carlos III de Madrid titulado originalmente "Transición a las ECAI's. Aspectos Jurídicos y Aspectos Empresariales", galardonado con el premio a TFG en la I Edición de los premios de Investigación Pilar Azcárate de Trabajos de Fin de Grado, Trabajo Fin de Máster y Tesis Doctorales en materia de Género e Igualdad de Oportunidades por Resolución del Rector de la Universidad Carlos III de Madrid de 21 de diciembre de 2015.

** La autora desea agradecer a la Dra. Celia M. Caamiña Dominguez su atención y colaboración en el desarrollo de esta investigación. También desea la autora agradecer la colaboración de todos los profesionales y familias adoptivas que han contribuido con su experiencia y conocimientos a enriquecer la investigación desde un punto de vista práctico y social.
} 
Adopción Internacional en la Fase Administrativa de Instrucción. 1. Evolución hacia los Organismos Acreditados para la Adopción Internacional. Razones de su aparición. 2. Los Organismos Acreditados para la Adopción Internacional. A) Constitución y acreditación. B) Funciones y actividades. C) Régimen de funcionamiento y obligaciones. D) Régimen económico y financiero. E) Supervisión y control. F) La relación jurídica entre los solicitantes de adopción internacional y el Organismo Acreditado para la Adopción Internacional. IV. Conclusiones sobre el proceso de adopción internacional en España y sobre la intervención de los Organismos Acreditados para la Adopción

\section{Introducción}

1. La aparición de los Organismos Acreditados para la Adopción Internacional en nuestro país, conocidos como Entidades Colaboradoras de Adopción Internacional antes de la reforma operada en la Ley de Adopción Internacional en el año 2015 que trataremos posteriormente, es relativamente reciente y la misma ha propiciado notables cambios en el ámbito jurídico. Estos organismos son empresas privadas constituidas bajo una figura jurídica que las define como entidades sin ánimo de lucro, que desarrollan ciertas funciones delegadas por la entidad autonómica competente en materia de adopción internacional, en la Fase Administrativa de Instrucción del proceso de adopción Internacional a través de una acreditación autonómica, sin la cual no pueden operar en ningún caso en el tráfico jurídico.

2. Desde el ámbito jurídico resulta interesante estudiar la repercusión y la evolución que ha tenido la inclusión de agentes privados en el proceso de adopción internacional, teniendo en cuenta que anteriormente todo el proceso de tramitación de adopciones internacionales había estado en manos de agentes públicos. Esta delegación de funciones en organismos privados ya se había producido anteriormente en varios países, los cuales habían incluido en el proceso de adopción internacional a organismos privados equivalentes a los Organismos Acreditados para la Adopción Internacional, sin embargo en España esta inclusión de agentes privados es, como ya hemos comentado, bastante reciente.

3. Para ello, se plantea una investigación que parte de un breve estudio sobre el proceso de constitución de las adopciones internacionales, el cual se centra en las notables deficiencias encontradas en la fase post-adoptiva que hacen peligrar el objetivo final de la institución jurídica de la adopción internacional, para pasar a estudiar posteriormente las tareas delegadas a los Organismos Acreditados para la Adopción Internacional así como su regulación y funcionamiento de una manera pormenorizada.

\section{La Adopción Internacional en Derecho Internacional Privado Español}

\section{Breve referencia a las vías de constitución de adopciones internacionales en España con espe- cificación de las tareas delegadas a los Organismos Acreditados para la Adopción Internacional}

\section{A) Adopción Internacional constituida ante Autoridad Española}

4. El procedimiento de adopción internacional constituida ante Autoridad Española tiene en España dos fases totalmente diferenciadas: la fase administrativa previa a la adopción y la constitución de la adopción por juez español ${ }^{1}$. Antes de desarrollar estas dos fases, es necesario recordar que la adopción en España se configura como una institución de protección de menores, y por lo tanto el régimen jurídico

${ }^{1}$ La Adopción Publificada es uno de los es uno de los tres modelos de adopción que podemos encontrar en el mundo junto con la Adopción Privada y la Anti-Adopción. Vid. A. L. Calvo Caravaca/J. Carrascosa González, Capitulo XX Adopción Internacional, en A. L. Calvo Caravaca/J. Carrascosa González (dirs.), Derecho Internacional Privado, Vol. II, Granada, Comares, 2013, p. 325 y 326; A. L. Calvo Caravaca/J. Carrascosa González, La ley 54/2007 de 28 de diciembre 2007 sobre adopción internacional (Reflexiones y comentarios), Granada, Comares, 2008, p. 11 y ss..; B. L. CARRILlo CARRILlo, Adopción Internacional y Convenio de la Haya de 29 Mayo 1993, relativo a la protección del niño y a la cooperación en materia de Adopción Internacional, Tesis de Doctorado para la obtención del título de Doctora en Derecho, Universidad de Murcia, Murcia, 2003, p. 30 y ss. 
de la institución debe estar presidido por el principio favor minoris ${ }^{2}$, y de acuerdo con el principio de publificación de la adopción, los trámites para constituir las adopciones internacionales deben realizarse bajo el control de las Autoridades Públicas competentes.

\section{a) Fase Administrativa de Instrucción}

5. La Fase Administrativa de Instrucción o Fase Administrativa Previa engloba los primeros trámites necesarios para la constitución de una adopción internacional por las Autoridades españolas. Esta primera fase es necesaria siempre, y se desarrolla ante las autoridades administrativas españolas, por lo que esta fase del procedimiento tiene un carácter administrativo y se regula consecuentemente por normas de Derecho Administrativo ${ }^{3}$. En general, las Entidades Públicas Administrativas competentes para instruir esta fase son Entidades Públicas de las Comunidades Autónomas, y aunque en la Ley 54/2007, de 28 de diciembre de Adopción Internacional ${ }^{4}$ (LAI) se establecen unas normas mínimas para fijar ciertos estándares orientados a la uniformidad de los procedimientos, cada Comunidad Autónoma añade sus propias normas y requisitos ${ }^{5}$. Por todo lo anterior, a partir de este momento tendremos en cuenta la legislación vigente en la Comunidad de Madrid para realizar el estudio de esta fase del proceso de adopción internacional.

Los trámites a realizar en la Fase Administrativa de Instrucción son dos, en primer lugar el control de la idoneidad de los adoptantes (art. $176 \mathrm{CC}$ ), y en segundo lugar la realización de la propuesta previa de adopción internacional ${ }^{6}$. Vamos a estudiar brevemente cada uno de los trámites por separado.

6. Antes de ocuparnos del certificado de idoneidad, cabe señalar que antes de la obtención del mismo existe una fase de formación obligatoria para los potenciales adoptantes ${ }^{7}$. El principal objetivo de la formación es capacitar a los futuros padres adoptivos para que sepan hacer frente a la adopción y que esta al final sea exitosa ${ }^{8}$. Tras la formación comienza la valoración psicosocial de los adoptantes.

7. El certificado de idoneidad, que de acuerdo con lo establecido en el artículo 5.1 d) de la LAI será expedido por las Entidades Públicas, previa elaboración del informe psicosocial directamente por las Entidades Públicas o a través de instituciones o entidades debidamente autorizadas, tiene un objetivo extremadamente relevante que es determinar si los potenciales adoptantes, reúnen las aptitudes necesarias para cubrir las necesidades del menor, así como determinar igualmente que cumplirán las obli-

2 Es en el CH 1993 en el que este principio tiene un papel fundamental. En el mismo, se establece además que los niños deben ser atendidos siempre que se pueda en su país de origen, planteándose la adopción internacional como una opción en un segundo plano.; Además, la adopción debe estar orientada a proteger y respetar los derechos del niño, garantizando siempre su interés superior, tal y como aparece expresamente recogido en la Convención sobre los Derechos del Niño de 1989, adoptada por la Asamblea General de las Naciones Unidas el 20 de noviembre de 1989. Ratificada por España el 30 de Noviembre de 1990, BOE núm. 313, de 31 de diciembre de 1990, p. 38897 a 38904. [Web en línea], [fecha de consulta: 13 mayo 2016], Disponible en: < https://www.boe.es/buscar/doc.php?id=BOE-A-1990-31312>.

Artículo 3.1.: En todas las medidas concernientes a los niños que tomen las instituciones públicas o privadas de bienestar social, los tribunales, las autoridades administrativas o los órganos legislativos, una consideración primordial a que se atenderá será el interés superior del niño.; Vid. J. A. Aunión/J. ReINoso, Adopción Internacional como último recurso, [Documento en línea], Diario El País, 8 de enero de 2013, [fecha de consulta: 13 mayo 2016], Disponible en: < http://sociedad.elpais.com/ sociedad/2013/01/08/actualidad/1357669110_681834.html>.

3 A. L. Calvo Caravaca/J. Carrascosa González, Capitulo XX Adopción Internacional, Op. Cit., p. 331 y 332.

${ }^{4}$ Ley 54/2007, de 28 de diciembre, de Adopción internacional. BOE núm. 312, de 29 de diciembre de 2007, p. 53676 a 53686. [Documento en línea], [fecha de consulta: 30 mayo 2016], Disponible en: $<$ https://www.boe.es/buscar/act.php?id=BOEA-2007-22438>

5 A. L. Calvo Caravaca/J. Carrascosa González, Capítulo XX Adopción Internacional, Op. Cit., p. 331 y 332.

${ }^{6}$ A. L. Calvo Caravaca/J. Carrascosa GonzÁlez, Capítulo XX Adopción Internacional, Op. Cit., p. 331 y 332

7 Comunidad de Madrid, Instituto Madrileño del Menor y la Familia, Obtención del certificado de idoneidad, [Documento en línea], [fecha de consulta: 13 mayo 2016], Disponible en: $<$ http://www.madrid.org/cs/Satellite?blobcol=urldata\&blo bheader $=$ application $\% 2 \mathrm{Fpdf} \&$ blobheadername $1=$ Content-Disposition\&blobheadervalue $1=$ filename $\% 3 \mathrm{DCertificado}+\mathrm{de}+\mathrm{idon}$ eidad.pdf\&blobkey=id\&blobtable=MungoBlobs\&blobwhere $=1352846009747 \&$ ssbinary $=$ true $>$.

8 M. D. VÁzquez Morillo/M. León Muñoz, Módulo 2, Capítulo 5. Formación para solicitantes de adopción, en R. Martínez/J. M. Gómez (dirs.) La adopción de menores: Retos y necesidades, Sevilla, Asociación Andaluza de Ayuda a la Adopción y a la Infancia, 2008, p. 145. [Documento en línea], [fecha de consulta: 13 mayo 2016], Disponible en: < http:// asociacionllar.org/user/files/libro_adopcion.pdf>. 
gaciones legales, ofreciendo al menor que quieren adoptar el afecto y el cuidado debido'. Es relevante tener presente que en esta etapa los adoptantes se encuentran sometidos a una situación de gran estrés y ansiedad, ya que pueden considerar que este proceso es una intrusión en su intimidad, y porque es probable que muchos de los adoptantes ya hayan pasado por varias situaciones emocionalmente dolorosas ${ }^{10}$.

8. La obtención del certificado de idoneidad de los adoptantes, el cual tiene una validez de tres años ${ }^{11}$, se realiza mediante un estudio psicosocial de los mismos a través de entrevistas y visitas al domicilio, en las que los profesionales podrán incluir los cuestionarios o pruebas que consideren necesarios para realizar la valoración, y en los que tendrán en cuenta criterios como la edad, los ingresos económicos así como la salud física y mental entre otros ${ }^{12}$. Cuando los profesionales dispongan de toda la información necesaria será cuando decidan sobre la idoneidad o no de la familia.

9. Todo lo que hemos visto hasta ahora sobre el certificado de idoneidad es lo que establece la Ley al respecto del mismo, no obstante es interesante obtener una visión práctica para comprobar si realmente el mismo es útil y eficaz en el proceso de adopción internacional, para ello contamos con la opinión de A. Fernández-Martos Abascal ${ }^{13}$, que desarrolla actualmente su carrera como psicólogo en la Universidad Carlos III de Madrid, y en el pasado desarrolló su carrera profesional en la Fundación Meniños ${ }^{14}$ en el ámbito de acogimiento familiar. En su opinión el certificado de idoneidad es necesario, es un método mediante el que podemos obtener información valiosa sobre los adoptantes, sobre sus capacidades y motivaciones, que en definitiva van a ser dos de los factores que más influencia van a tener en el proceso post-adoptivo. A. FerNÁndez-MARTOs tiene además una visión propia sobre la utilidad del certificado de idoneidad, desde su punto de vista los trámites que engloban la adquisición del certificado de idoneidad son oportunidades para hacer reflexionar a la familia, para que se replanteen sus capacidades y motivaciones, y que si tras esa reflexión llegan a la conclusión de que realmente no están preparados para recibir en la familia a un niño adoptado que sean ellos mismos los que opten por retirarse del proceso de adopción.

10. El segundo paso de la fase administrativa de instrucción o fase administrativa previa es la realización de la propuesta previa de adopción internacional, trámite que se encuentra regulado en el Convenio de la Haya de 1993 relativo a la Protección del Niño y a la Cooperación en materia de Adopción Internaciona $1^{15}$ (CH 1993), convenio en el cual España es parte ${ }^{16}$. El referido Convenio establece un

9 G. Marmolejo Vera/M. I. López Góngora, Módulo 3, Capítulo 6. La valoración psicosocial de los solicitantes de adopción, en R. Martínez/J. M. Gómez (dirs.) La adopción de menores: Retos y necesidades, Sevilla, Asociación Andaluza de Ayuda a la Adopción y a la Infancia, 2008, p. 145. [Documento en línea], [fecha de consulta: 13 mayo 2016], Disponible en: < http:// asociacionllar.org/user/files/libro_adopcion.pdf>.

10 Ibídem. p. 146 y 147.; Marta Bertran /Victòria Badia, "El tiempo de espera en la adopción: ¿tiempo de riesgo o de formación para la prevención para las familias?", Aloma: revista de psicologia, ciències de l'educació i de l'esport, n⿳32, [Documento en línea], 2014, [fecha de consulta: 13 mayo 2016]. Disponible en: < http://www.raco.cat/index.php/Aloma/article/ view/284549/372457>.; A. Berástegui Pedro-Viejo, "El tiempo de la espera en la adopción internacional: vivencia de la espera y estrategias de afrontamiento", Psicothema, Vol. 20, nº4, [Documento en línea], 2008, [fecha de consulta: 13 mayo 2016], Disponible en: $<$ http://www.psicothema.com/pdf/3522.pdf $>$.;

11 G. Marmolejo Vera/M. I. López Góngora, Módulo 3, Capitulo 6. La valoración psicosocial de los solicitantes de adopción, Op. Cit, p. 147.

12 Para profundizar en cada uno de los criterios expuestos Vid. G. Marmolejo Vera/M. I. López Góngora, Módulo 3, Capítulo 6. La valoración psicosocial de los solicitantes de adopción, Op. Cit, p. 149 y ss.; Ley 6/1995, de 28 de marzo, de Garantías de los Derechos de la Infancia y la Adolescencia en la Comunidad de Madrid. BOE núm. 183, de 2 de agosto de 1995, p. 18545 a 23688. [Web en línea], [fecha de consulta: 13 mayo 2016], Disponible en: < https://www.boe.es/boe/dias/1995/08/02/ pdfs/A23670-23688.pdfs.

13 Entrevista realizada en el año 2015.

14 Fundación Meniños, [Web en línea], [fecha de consulta: 13 mayo 2016], Disponible en: < https://www.meninos.org/ quien_somos_es.htm>

${ }^{15}$ Instrumento de ratificación del Convenio relativo a la protección del niño y a la cooperación en materia de adopción internacional, hecho en La Haya el 29 de mayo de 1993. BOE núm. 182, de 1 de agosto de 1995, p. 23447 a 23454 [Web en línea], [fecha de consulta: 13 mayo 2016], Disponible en: < https://www.boe.es/diario_boe/txt.php?id=BOEA-1995-18485>.

${ }^{16} \mathrm{HCCH}$ (Hague Conference on Private International Law), Estado actual del Convenio de 29 de mayo de 1993 
reparto distributivo de competencias administrativas entre las autoridades administrativas de los Estados parte $^{17}$, por lo que no debemos olvidar que estamos en la fase previa de constitución de la adopción la cual es netamente administrativa. Este reparto de competencias, y en definitiva la tramitación de la propuesta previa de adopción internacional viene regulada en el Capítulo IV ("Condiciones de procedimiento respecto a las adopciones internacionales") del Convenio de la Haya de 1993.

b) Fase Judicial de Constitución

11. En España, emitida la propuesta previa de adopción por la Entidad Pública competente se pasa a la fase judicial de constitución de la adopción, la cual, como ya hemos comentado, ha de desarrollarse necesariamente ante un juez español competente para ello $^{18}$. Dicha competencia se determina por los foros de competencia establecidos en el artículo $14 \mathrm{LAI}^{19}$, determinándose la competencia objetiva y territorial del órgano jurisdiccional competente en el artículo 16 LAI, que remite a las normas de jurisdicción voluntaria y en su defecto al órgano judicial elegido por los adoptantes.

12. En cuanto a la Ley aplicable a la adopción internacional, actualmente únicamente cabe la aplicación de la Ley española de acuerdo con el artículo 18 LAI, y en consonancia también con la reciente derogación del artículo 21 de la LAI por la Ley 26/2015. No obstante, encontramos dos excepciones ${ }^{20}$ a esta regla general de aplicación de la Ley española a la constitución de la adopción en los artículos 19 LAI y 20 LAI, cuyo principal objetivo es evitar las llamadas "adopciones claudicantes"21.

\section{B) Adopción Internacional constituida ante Autoridad Extranjera}

13. Ante la existencia de una adopción internacional constituida ante autoridad extranjera el artículo 25 LAI establece dos itinerarios posibles para su reconocimiento. Estos itinerarios posibles son por un lado el régimen específico del Convenio de la Haya de $1993^{22}$, que propone un reconocimiento basado en la confianza entre los países parte en el mismo, y por otro lado el régimen de producción interna ${ }^{23}$ que se basa al contrario que el anterior, en la desconfianza en el país extranjero de constitución de la adopción, al no existir ninguna norma internacional entre los dos países. Por su parte, deberá tenerse en cuenta lo dispuesto en el artículo 31 LAI referente a la aplicación del orden público internacional en el reconocimiento las adopciones menos plenas constituidas ante autoridades extranjeras.

\section{El procedimiento post-adoptivo}

14. En el momento en el que la adopción se constituye, los adoptantes y el adoptado pasan a formar una familia como las demás, pudiendo considerar así que en la sociedad española conviven distintos

relativo a la Protección del Niño y a la Cooperación en materia de Adopción Internacional, [Web en línea], [fecha de consulta: 13 mayo 2016], Disponible en: $<$ http://www.hcch.net/index_es.php?act=conventions.status\&cid=69>.

17 A. L. Calvo Caravaca/J. Carrascosa González, Capítulo XX Adopción Internacional, Op. Cit., p.364.

18 A. L. Calvo Caravaca/J. Carrascosa González, Capítulo XX Adopción Internacional, Op. Cit., p. 335. Adopción Consular: Si bien es cierto que hasta ahora hemos venido diciendo que la fase de constitución de las adopciones internacionales es una fase exclusivamente judicial, debemos hacer una matización. "A pesar de que la adopción consular ha sido una institución criticada por suponer una intrusión en las competencias de jueces y tribunales, el legislador la ha mantenido vigente en nuestro ordenamiento en virtud del principio de "interés superior del menor". En efecto, se considera que en las situaciones en las que a los menores adoptados no se les permite salir de su Estado de origen, ni tampoco es posible constituir la adopción en ese país, los cónsules españoles pueden constituir adopciones internacionales con arreglo a los criterios establecidos en el artículo 17 LAI".

19 A. L. Calvo Caravaca/J. Carrascosa González, Capítulo XX Adopción Internacional, Op. Cit., p. 332.

20 A. L. Calvo Caravaca/J. Carrascosa González, Capítulo XX Adopción Internacional, Op. Cit., p. 337 y 338.

21 A. L. Calvo Caravaca/J. Carrascosa González, Capítulo XX Adopción Internacional, Op. Cit., p.337. Adopciones claudicantes: las adopciones claudicantes son aquellas que son válidas en España, o en otro país concreto, pero inválidas en otros países que se encuentran conectados con la adopción internacional.

22 A. L. Calvo Caravaca/J. Carrascosa González, Capítulo XX Adopción Internacional, Op. Cit., p. 365 y ss.

23 A. L. Calvo Caravaca/J. Carrascosa GonzÁlez, Capítulo XX Adopción Internacional, Op. Cit., p. 345 y 346. 
modelos de familia, todos ellos protegidos por la Constitución Española en su artículo 39.1, incluyendo por tanto entre dichos modelos la familia adoptiva ${ }^{24}$. A partir de este momento, tras la constitución judicial de la adopción, encontramos poca regulación relativa al proceso post-adoptivo al que se enfrenta la familia y el menor, no obstante, consideramos que estamos ante una de las fases más importantes para la familia, y que la misma debe ser integrada en el proceso de adopción propiamente dicho y no quedar como una fase secundaria, ya que podemos afirmar que realmente es en este momento del proceso en el que se va a determinar el éxito o fracaso de la adopción.

15. Si bien es cierto que la mayoría de las familias adoptivas logran una integración familiar plena, la adopción es un camino diferente al habitual para formar una familia, y que por ello surgen dificultades para sus miembros que derivan en gran parte de las circunstancias que cada uno de ellos trae consigo y del propio proceso para formar una familia a través de la adopción ${ }^{25}$, sin contar con la estigmatización que en ocasiones sufren las familias adoptivas ${ }^{26}$. Esto hace que por las dificultades de los padres o de los hijos no se llegue a desarrollar el sentimiento de pertenencia familiar que sin duda consideramos imprescindible para que la adopción resulte exitosa ${ }^{27}$. Esos problemas a los que se enfrenta la familia adoptiva pueden desembocar en la ruptura de la adopción, que se produce con unas tasas muy variables dependiendo de múltiples factore ${ }^{28}$, no habiéndose establecido una tasa real de fracaso uniforme. Estos factores denominados "de riesgo" pueden provenir tanto de los padres ${ }^{29}$ como del niño ${ }^{30}$, e incluso también de la Administración ${ }^{31}$.

16. Estas dificultades que pueden surgir en el seno de la familia adoptiva, y que pueden desembocar en la ruptura de la familia, requieren un abordaje por parte de profesionales para evitar precisamente esa ruptura. En esta línea, el Convenio de la Haya de 1993 reclama que las Autoridades Centrales de los Estados asuman una serie de funciones para proteger a los niños adoptados y para facilitar la integración familiar, es decir reclama que los Estados establezcan una serie de servicios de post-adopción que sirvan de apoyo a la familia adoptiva. Además, es relevante que los profesionales que presten estos servicios post-adoptivos a las familias estén adecuadamente formados atendiendo a las necesidades específicas que presentan las familias adoptivas ${ }^{32}$.

${ }^{24}$ P. Blanco-Morales Limones, "Una filiación: tres modalidades de establecimiento. La tensión entre la ley, la biología y el afecto”, Bitácora Millennium DIPr: Derecho Internacional Privado, $\mathrm{n}^{\circ}$ 1, [Documento en línea], 2015, [fecha de consulta: 13 mayo 2016], Disponible en: < http://www.millenniumdipr.com/ba-4-una-filiacion-tres-modalidades-de-establecimiento-latension-entre-la-ley-la-biologia-y-el-afecto>.

${ }^{25}$ B. M. Piqueras Alegre, Módulo 4, Capitulo 7. El servicio Postadopción, en R. Martínez/J. M. Gómez (dirs.) La adopción de menores: Retos y necesidades, Sevilla, Asociación Andaluza de Ayuda a la Adopción y a la Infancia, 2008, p. 163. [Documento en línea], [fecha de consulta: 20 mayo 2016], Disponible en: < http://asociacionllar.org/user/files/libro_adopcion.pdf>.

${ }^{26}$ M. J. RodrígueZ-JaUme/D. JAREÑo Ruiz, "Estigma social y adopción internacional en España. ¿Es la familia adoptiva un modelo familiar menos «auténtico» que los basados en lazos biológicos?”, Papers: revista de sociología, Vol. 100, n², [Documento en línea], 2015, [fecha de consulta: 13 mayo 2016], Disponible en: < http://ddd.uab.cat/pub/papers/papers_a2015m46v100n2/papers_a2015m4-6v100n2p211.pdf>.

27 L. Parrondo, "Especialización Profesional en los Servicios de Apoyo Postadoptivo", Adopciones, Familias, Infancias", No8, p.1 [Documento en línea], 2009, [fecha de consulta: 20 mayo 2016], Disponible en: < http://ddd.uab.cat/pub/afin/afinSPA/ afin_a2009m10n8iSPA.pdf $>$.

${ }_{28}$ A. Berástegur Pedro-Viejo, Las adopciones internacionales truncadas y en riesgo en la Comunidad de Madrid, Madrid, Consejo Económico y Social de la Comunidad de Madrid, 2003, p. 30;

29 C. Palavecino/P. Rodríguez/N. Zicavo, "Vivencias de personas que optaron por la parentalidad adoptiva", Ciencias Psicológicas, Vol. 9, n², [Documento en línea], 2015, [fecha de consulta: 13 mayo 2016], Disponible en: < http://www.scielo. edu.uy/scielo.php?script $=$ sci_arttext\&pid=S1688-42212015000300004>.

30 Ibídem. P. 163 y 164.; Grupo de desarrollo de la Guía CORA, "Consenso en adopción internacional. Consenso en adopción internacional. Extracto de la Guía CORA para pediatras y otros profesionales sanitarios”. Revista Pediatría Atención Primaria, Vol. XI, nº17, [Documento en línea], 2009, [fecha de consulta: 13 mayo 2016], Disponible en: < http://www.pap.es/ FrontOffice/PAP/front/Numero-Actual-/-Suplementos/Detalle-Revista/Suplemento/_xLYQxcKpAdooGUqYNVybzVXC2UCogNGUJ_gvvdlEiDc $>$.

31 B. M. Piqueras Alegre, Módulo 4, Capítulo 7. El servicio Postadopción, Op. Cit., p. 163

32 L. PArrondo, "Especialización Profesional en los Servicios de Apoyo Postadoptivo", Adopciones, Familias, Infancias", Op. Cit., p. 12 y 13. 
17. En España los Servicios de post-adopción han ido instaurándose de manera muy lenta en las diferentes Comunidades Autónomas. Estos servicios se presentan como servicios de ayuda a las familias, tanto para las personas que han adoptado como a las que han sido adoptadas para poder afrontar las dificultades que plantea la integración familiar en los procesos de adopción. Sin embargo, la mayoría de las veces la concepción del servicio de post-adopción no es el que hemos estado exponiendo hasta ahora, sino que la post-adopción se concibe como una serie de controles, los denominados informes de seguimiento que se realizan a petición de los Estados de origen de los menores adoptados elaborados por diferentes entidades dependiendo de cómo se haya tramitado la adopción. En el caso particular de la Comunidad de Madrid, encontramos en una guía explicativa para las familias adoptantes ${ }^{33}$ la existencia del sistema de control y también la existencia de un sistema de apoyo más psicológico y social orientado a la integración familiar.

18. Si cambiamos de perspectiva, y nos ponemos de nuevo en la piel de la familia adoptiva que necesita apoyo psicológico y social, encontramos en la Comunidad de Madrid recursos y servicios como el programa "APOSTAD" (que viene de A-poyo POST AD-optivo) o los CAEF's (Centro de Apoyo y Encuentro Familiar). No obstante cabe matizar que estos últimos no están especializados en Adopción Internacional, sino que prestan ayuda a las familias en temas variados, como por ejemplo divorcios o problemas de convivencia familiar.

19. En relación con la eficacia práctica de los servicios de este recurso, contamos con la opinión de S. GARrigos, coordinadora del CAEF Alcorcón-Móstoles ${ }^{34}$. Desde el punto de vista de S. Garrigos, hay varios aspectos a mejorar en los servicios que se ofrecen en los centros, entre ellos, y uno de los más importantes para el proceso post-adoptivo es la orientación psicológica que se ofrece a las familias. Los CAEF ofrecen tres sesiones de terapia psicológica y una sesión de seguimiento, número de sesiones que suele ser insuficiente para tratar problemas en el proceso de post-adopción, por ello cuando el número de sesiones se considere insuficiente en un caso concreto, los usuarios serán derivados a uno de los siete CAF's del Ayuntamiento de Madrid que ofrecen un servicio más profundo y completo en orientación psicológica. En el mismo sentido, considera que hacen falta en términos generales más profesionales con una formación específica en materia de post-adopción que sean capaces de entender y abordar la problemática de esos menores y familias, la cual nada tiene que ver con la problemática que pudiera presentar otro modelo de familia. "En el proceso de post-adopción muchas familias demandan acompañamiento, el cual es difícil de obtener tanto a nivel público como a nivel privado, no hay profesionales debidamente formados y tampoco hay una información clara sobre los servicios que se ofrecen", asegura S. GARRIGos.

20. Contamos también en este punto con la opinión del psicólogo A. Fernández-Martos, el cual coincide con lo expuesto sobre el seguimiento que a día de hoy se realiza a la familia adoptiva. Si bien es cierto que las entrevistas para realizar el informe de seguimiento son necesarias, el proceso post-adoptivo no debe centrarse sólo en ellas, este debe ser concebido como un apoyo para la familia adoptiva, y no sólo como un control social o una continua evaluación o examen sobre las capacidades parentales de los adoptantes. En opinión del psicólogo, el proceso post-adoptivo, entendido como un apoyo fundamental para la familia adoptiva, se ha relegado a un segundo lugar siendo los programas planteados bastante pobres e insuficientes, y surgiendo de este modo un gran número de asociaciones en las que padres adoptivos que no encuentran respuestas ni soluciones se agrupan para buscarlas.

21. Por último, y en relación con la búsqueda de apoyo por parte de las familias adoptivas en asociaciones, contamos con una entrevista realizada a la Asociación ATLAS ${ }^{35}$ en defensa de la Adopción. Al

33 A. Berástegui Pedro-Viejo/B. Gómez Bengoechea/S. Adroher Biosca, Adopción Internacional en la Comunidad de Madrid, Madrid, Instituto Madrileño del Menor y la Familia, 2007, p. 59 y ss. [Documento en línea], [fecha de consulta: 20 mayo 2016], Disponible en: < http:/www.madrid.org/cs/Satellite?blobcol=urldata\&blobheader=application\%2Fpdf\&blobhea dername $1=$ Content-Disposition\&blobheadervalue $1=$ filename\%3D1362-WEB.pdf\&blobkey=id\&blobtable=MungoBlobs\&blo bwhere $=1202799915366 \&$ ssbinary $=$ true $>$.

34 Entrevista realizada en el año 2015.

${ }^{35}$ La Asociación ATLAS se funda en 1997 por cuatro familias que habían adoptado internacionalmente y la razón principal 
hablar de la fase post-adoptiva en el procedimiento de adopción internacional, consideran que los servicios y facilidades que se ofrecen tanto desde el ámbito público como desde los OAA's son, desde su propia experiencia muy escasos. Por último cabe señalar que la Asociación ATLAS lucha sobre todo en el campo de la escolarización de los menores adoptados ${ }^{36}$, en el que consideran que queda mucho por hacer para que la adaptación de los menores a su nueva familia y entorno se desarrolle de la mejor manera posible.

22. En definitiva, podemos afirmar que el proceso de post-adopción concebido como un proceso psicológico de adaptación del menor a su nueva familia y a su nuevo entorno, y de adaptación de la familia al menor, queda relegado a un segundo plano, ya que tal y como adelantábamos al principio hoy en día el proceso post-adoptivo se centra en las entrevistas de seguimiento y control exigidas por el país de origen de los menores y no en la adaptación real de los mismos.

\section{La intervención de los Organismos Acreditados para la Adopción Internacional en la Fase Administrativa de Instrucción}

23. La tramitación de las adopciones internacionales en España (constitución de adopción internacional ante Autoridad española) se divide en dos fases claramente diferenciadas, como ya hemos estudiado. En primer lugar encontramos la Fase Administrativa de Instrucción o Fase Administrativa Previa, la cual tiene carácter administrativo y engloba los primeros trámites necesarios para la constitución de la adopción internacional. En segundo lugar tenemos la Fase Judicial de Constitución de la adopción internacional, la cual ha de desarrollarse necesariamente ante un juez español competente para ello. Es en la primera fase Administrativa de Instrucción donde se brinda a los solicitantes de adopción internacional la oportunidad de elegir entre diferentes vías para la tramitación del expediente, no siendo posible realizar ningún tipo de elección en la Fase de Constitución ya que, esta fase es exclusivamente judicial.

24. A lo largo del proceso de valoración de los adoptantes y una vez emitido el certificado de idoneidad, los solicitantes de adopción internacional deberán decidir la vía de tramitación del expediente, pudiendo elegir entre tramitar el mismo a través de las Administraciones Públicas españolas competentes, o a través de un Organismo Acreditado para la Adopción Internacional (conocido como Organismo Acreditado para la Adopción, de aquí en adelante OAA), anteriormente conocido como Entidad Colaboradora de Adopción Internacional (ECAI):

- Protocolo Público: como ya sabemos, España ratificó el CH 1993 y de acuerdo a la exigencia establecida en su artículo 6 España estableció 17 Autoridades Centrales diferentes, una por cada comunidad autónoma ${ }^{37}$; al ser la protección de menores una competencia de las distintas comunidades autónomas, el expediente será tramitado en los Servicios de Protección de Menores o Servicios Específicos de Adopción de las mismas ${ }^{38}$. De esta forma, los solicitantes

fue la falta de información que se ofrecía a las familias que querían o que habían adoptado a un menor. A día de hoy la asociación sigue dando apoyo a las familias sin ningún ánimo de lucro, orientando tanto a aquellas personas que quieren adoptar, como aquellas que están en pleno procedimiento de adopción, y también a aquellas que ya tienen menores adoptados, tanto nacionales o internacionales.

36 Para más información sobre la inclusión educativa de los menores Vid. Ma A. Espino Bravo/A. M. Casino García/L. I. LlinARES INSA, "Familia, escuela y adopción internacional. La inclusión educativa", Familia: Revista de ciencias y orientación familiar, $n^{\circ} 48$, [Documento en línea], 2014, [fecha de consulta: 13 mayo 2016], Disponible en: < http://summa.upsa.es/viewer. vm?id=0000032908\&page $=1$ \&search $=\&$ lang $=$ es\&view $=$ main $>$.

37 A. Cerqueiro Nuñez, Xunta de Galicia, Las Entidades Colaboradoras de Adopción Internacional, [Documento en línea], 2013, p.8 [fecha de consulta: 20 mayo 2016]. Disponible en: < http://adopcions.xunta.es/files_editor/file/guia\%20 ecai\%20castellano.pdf>.

38 M. A. Calzadilla Medina, La adopción internacional en el Derecho español, Colección Monografías de Derecho Civil, I. Persona y Familia, Madrid, Dykinson, 2004, p. 166.; MSSSI, GoBIERno DE EsPaÑA, Dónde acudir si quieres tramitar una Adopción Internacional: recursos públicos y privados en España, [Documento en línea], 2008, p. 26, [fecha de consulta: 13 mayo 2016]. Disponible en: <http://www.msssi.gob.es/ssi/familiasInfancia/docs/agendaRecursosAdopcion.pdf>; MSSSI, Gobierno de España, [Web en línea], [fecha de consulta: 20 mayo 2016]. Disponible en: $<$ http://www.msssi.gob.es/ssi/familiasInfancia/adopciones/adopInternacional/procedAdopcion/etapasTramitacion.htm> 
de adopción internacional deberán dirigir toda la documentación del expediente de adopción internacional a la Autoridad Central de su Comunidad Autónoma para que esta la remita al país de origen y se coordine con las correspondientes autoridades para la tramitación de la solicitud de adopción internacional.

- Organismo Acreditado para la Adopción Internacional: Si se opta por la tramitación a través del citado organismo, la Autoridad Central competente de la comunidad autónoma enviará al OAA los documentos administrativos y esta será la encargada de completar el expediente y remitirlo a la persona que la represente en el país de origen del menor para su presentación ante las autoridades competentes de este último ${ }^{39}$.

25. La posible elección de una u otra vía para la tramitación del expediente de adopción internacional dependerá de dos circunstancias ${ }^{40}$ :

- En primer lugar, si el país de origen del menor ha fijado o no una vía exclusiva para el trámite de los expedientes de adopción internacional. En este sentido, países como la India o Bolivia han optado por que la tramitación de los expedientes de adopciones internacionales se realice de forma exclusiva a través de OAA's, lo que reduce las posibilidades de los solicitantes de adopción en estos países a una vía.

- En segundo lugar, si la Administración General del Estado, en colaboración con las Entidades Públicas españolas, haya acordado que en determinado Estado se van a tramitar las solicitudes de adopción internacional a través de los OAA's tal y como se establece en el párrafo cuarto del artículo 6.2 LAI. En este caso ocurre lo mismo que en el anterior, las posibilidades de tramitación de los solicitantes de adopción internacional se reducen a la tramitación a través de un OAA.

26. De acuerdo a todo lo anterior, podemos establecer que en ningún caso es obligatoria la tramitación del expediente de adopción internacional a través de un OAA, excepto que el país de origen o de recepción del menor así lo exija, y que por lo tanto, a excepción de los dos casos comentados, los solicitantes podrán elegir libremente entre la tramitación a través de la Autoridad Pública competente, o a través de un OAA.

27. Esta posibilidad de elección en cuanto a la vía de tramitación del expediente de adopción internacional que se ofrece a los solicitantes nace gracias al CH 1993, el cual ofrece a las Autoridades Centrales de los Estados parte la posibilidad de delegar en su artículo 22.141. La misma Conferencia de la Haya, ha publicado una Guía de Buenas Prácticas titulada "Acreditación y organismos acreditados para la adopción: Principios generales y Guía de Buenas Prácticas n²", en la que se establecen ciertos estándares orientados a que la acreditación de los organismos acreditados de los Estados parte en el CH 1993 se realice de forma que se cumplan los objetivos del CH 1993 referidos a este tipo de organismos. Esta guía, a pesar de no ser vinculante para los Estados, ofrece una oportunidad de aumentar la seguridad jurídica de los mismos en materia de organismos acreditados y acreditación de los mismos a través de una serie de recomendaciones. Ese aumento de la seguridad jurídica repercute de forma positiva en las relaciones entre los países que tramitan solicitudes de adopción internacional, e indirectamente repercute también de forma positiva en los solicitantes de adopción internacional de los países.

28. Por último, cabe comentar otra vía posible para la tramitación de adopciones internacionales igualmente válida que las anteriores que hemos estudiado, pero que presenta mayores riesgos para los

\footnotetext{
39 A. Cerqueiro Nuñez, Op. Cit., p.9

40 MSSSI, Gobierno de España, [Web en línea], Op. Cit.; A. Cerqueiro Nuñez, Op. Cit., p.9; Para consultar los posibles itinerarios en los distintos países Vid. MSSSI, Gobierno de EsPaÑa, [Web en línea], [fecha de consulta: 20 mayo 2016], Disponible en: < http://www.msssi.gob.es/ssi/familiasInfancia/adopciones/adopInternacional/informPaisesOrigen/pdf/cuadro.pdf>

${ }^{41}$ Artículo 22.1 CH 1993: Las funciones atribuidas a la Autoridad Central por el presente Capitulo pueden ser ejercidas por autoridades públicas o por organismos acreditados conforme al Capitulo III, en la medida prevista por la ley de este Estado.
} 
solicitantes de adopción internacional y para el propio menor adoptando. Hablamos de las adopciones independientes ${ }^{42}$, en las que los adoptantes tramitan la adopción con ayuda de mediadores no acreditados. Este trámite se suele desaconsejar por considerarse que existe un riesgo elevado de encontrar supuestos de tráfico de menores, no obstante este tipo de adopciones pueden llevarse a cabo siempre que la legislación del país de origen no lo prohíba, ya que encontramos países de origen de los menores que exigen como requisito sine qua non que en la tramitación del procedimiento intervengan entidades acreditadas. A pesar de que esta vía de tramitación está abierta a los solicitantes de adopción internacional, debemos tener en cuenta que plantea dos grandes inconvenientes; por un lado podemos considerar que este tipo de adopciones atentan contra uno de los principios más importantes del procedimiento de adopción internacional, que es el de evitar el enriquecimiento por parte de los agentes que intervienen en el mismo, y por otra parte debemos tener en que a pesar de que no todas las adopciones independientes pueden calificarse como fraudulentas o negativas, sí es cierto que los factores de riesgo para la violación de los derechos de los menores adoptandos crecen notablemente ${ }^{43}$.

\section{Evolución hacia los Organismos Acreditados para la Adopción Internacional. Razones de su aparición}

29. Hasta el momento hemos hablado de la existencia de unos mediadores en el proceso de adopción internacional a los que los solicitantes de adopción internacional pueden acudir para tramitar el expediente de adopción denominados Organismos Acreditados para la Adopción Internacional o OAA's, sin embargo llegados a este punto cabe realizar una explicación más pormenorizada sobre estos organismos.

30. Los Organismos Acreditados para la Adopción Internaciona ${ }^{44}$, son entidades privadas sin ánimo de lucro, que tienen como finalidad en sus estatutos la protección de la infancia, acreditadas por la Autoridad competente de la Comunidad Autónoma en la que van a desarrollar su actividad, para realizar funciones de intermediación en los procesos de adopción internacional y autorizadas para ello por el organismo competente en materia de adopción en el país donde van a actuar ${ }^{45}$. La actividad de intermediación en la adopción internacional se define a su vez en el artículo 6.1 LAI: "Se entiende por intermediación en la adopción internacional toda actividad que tenga por objeto intervenir poniendo en contacto o en relación a los solicitantes de las adopción con las autoridades, organizaciones e instituciones del país de origen o residencia del menor susceptible de ser adoptado y prestar la asistencia suficiente para que la adopción se pueda llevar a cabo".

31. Como hemos podido comprobar hasta ahora, el procedimiento de adopción internacional es complejo, en el mismo intervienen diferentes legislaciones, diferentes autoridades y organismos con diferentes funciones y objetivos, e incluso nos encontramos con que los Estados tienen diferentes concepciones sobre la institución adoptiva y la familia ${ }^{46}$. Por todo ello, los OAA's se presentan como uno de los principales agentes especializados en la adopción internacional en los que las familias, desco-

42 M. A. Calzadilla Medina, Op. Cit, p. 188

43 Para más información Vid. M. A. CALZADILLA MEDINA, Op. Cit, p. 188 y ss.

44 Recordamos que con anterioridad a la entrada en vigor de la Ley 26/2015, de 28 de julio, de modificación del sistema de protección a la infancia y a la adolescencia, los Organismos Acreditados para la Adopción Internacional (OAA’s) se conocían como Entidades Colaboradoras de Adopción Internacional (ECAI's). Al ser tan reciente la modificación legislativa en muchos de los documentos que se mencionan se sigue haciendo referencia a la denominación ECAI, no obstante las funciones no han cambiado sino que simplemente lo ha hecho la denominación de los organismos. Por ello independiente de la denominación dada en los documentos y demás recursos utilizados a lo largo del texto se hará siempre referencia a la denominación OAA.

45 Artículo 6.2 LAI: La función de intermediación en la adopción internacional podrá efectuarse por las entidades públicas [...]. La función de intermediación en la adopción internacional podrá efectuarse por los organismos debidamente acreditados. Ninguna otra persona o entidad podrá intervenir en funciones de intermediación para adopciones internacionales.; MSSSI, Gobierno de España, [Documento en línea], Op. Cit., p. 27.

46 A. Cerqueiro NuñEZ, Op. Cit., p. 3. 
nocedoras del régimen jurídico que tiene la tramitación de la adopción en el país de origen del menor, desconocedoras de las Autoridades con las que deben contactar y desconocedoras, en general, de cómo tramitar los documentos preceptivos, depositan su confianza para la tramitación de los expedientes de adopción internacional.

32. Las dos principales causas que han llevado a la intervención de estos mediadores en la Fase Administrativa del proceso de adopción internacional, y consecuentemente a la regulación legal de los mismos son las siguientes:

- El aumento del número de solicitudes de adopción internacional que se ha producido en los últimos años, derivado en gran parte por el descenso de niños adoptables a través de la adopción nacional, ha hecho que las entidades públicas se hayan visto incapaces de tramitar tal volumen de expedientes de adopción internacional en un plazo de tiempo razonable, por lo que la posibilidad que se ha brindado a las entidades públicas de delegar ciertas funciones de mediación en los OAA's ha supuesto un desahogo para la administración pública y un ahorro de tiempo para los solicitantes de adopción ${ }^{47}$.

- Otra de las razones que ha llevado a la delegación de competencias a favor de los OAA's ha sido el objetivo de eliminar la mediación privada con ánimo de lucro ${ }^{48}$, que como ya hemos comentado anteriormente, pone en tela de juicio el respeto al interés del menor, principio que debe regir en cualquier procedimiento de adopción internacional.

\section{Los Organismos Acreditados para la Adopción Internacional}

33. Los Organismos Acreditados para la Adopción Internacional cuentan con un papel fundamental en el procedimiento de adopción internacional, y es por ello por lo que su regulación se ha desarrollado para garantizar que los mismos cumplen la legalidad existente. La normativa que regula a los OAA's se encuentra en tres niveles:

- Nivel Internacional. A nivel internacional los OAA's se encuentran regulados por el CH 1993, en el que se establecen las condiciones con las que deben contar las mismas para que las Autoridades Centrales puedan delegar funciones en ellas. Encontramos también en este nivel la Guía nº 2 de Buenas Prácticas de la Conferencia de la Haya que hemos venido mencionando, y que a pesar de no ser un instrumento vinculante para los Estados resulta de gran ayuda para lograr la uniformidad de la actividad de los organismos acreditados como los OAA's en los diferentes Estados.

- Nivel Nacional. La Ley nacional que regula los OAA's es la LAI, en la que, como posteriormente veremos con más detalle, en sus artículos 5 a 9 regula cuestiones como la acreditación o el seguimiento y control de los OAA's entre otras.

- Nivel Autonómico. En este punto, es importante recordar que las comunidades autónomas han asumido competencias en materia de protección de menores, encontrándose entre estas materias la regulación de los OAA's en su territorio. Es por ello por lo que deberemos acudir a la normativa propia de cada comunidad autónoma para conocer cómo se regula la actividad de los OAA's.

34. A continuación, vamos a estudiar cómo actúan en el tráfico de acuerdo a la normativa vigente los OAA's, para ello hemos elegido estudiar la situación de los mismos en la Comunidad Autónoma de Madrid, ya que de esta manera podremos profundizar y ejemplificar puntos que quedándonos en la situación general de la normativa estatal (LAI) no quedarían lo suficientemente claros.

47 M. Guzmán Peces, Op. Cit., p. 168; M. A. Calzadilla Medina, Op. Cit, p. 169.

48 M. Guzmán Peces, Op. Cit., p. 168. 
35. En este sentido, la normativa autonómica aplicable para nuestro estudio es la siguiente ${ }^{49}$ :

- Decreto 62/2003, de 8 de mayo, sobre acreditación, funcionamiento y control de las Entidades Colaboradoras de Adopción Internacional ${ }^{50}$.

- Orden 526/2013, de 20 de mayo, de la Consejería de Asuntos Sociales, por la que se desarrolla el Decreto 62/2003, de 8 de mayo, del Consejo de Gobierno de la Comunidad de Madrid, sobre acreditación, funcionamiento y control de las Entidades Colaboradoras de Adopción Internacional, y se establece el modelo oficial de contrato de mediación en Adopción Internacional ${ }^{51}$.

\section{A) Constitución y acreditación}

36. Los requisitos exigidos a los OAA's para obtener la acreditación necesaria para realizar sus actividades de intermediación en el procedimiento de adopción internacional se recogen en el artículo 7 de la LAI y en las normas de las Comunidades Autónomas, en concreto para la Comunidad de Madrid estos requisitos se encuentran en el Decreto 62/2003 en los artículos 6 a 14.

37. En primer lugar, las exigencias del artículo 7 de la LAI para la obtención de la acreditación son las siguientes:

- Los OAA's deben ser entidades sin ánimo de lucro. En este punto es interesante estudiar la forma jurídica que adoptan los OAA's teniendo en cuenta el principio de prohibición de ánimo de lucro ${ }^{52}$ que rige su actividad y a su vez estudiar también el significado de este principio.

Los OAA's podrán constituirse en asociaciones o fundaciones que estén legalmente constituidas e inscritas en el Registro correspondiente, siempre y cuando tengan por finalidad en sus estatutos la protección de menores, con ausencia de ánimo de lucro ${ }^{53}$. El ánimo de lucro impide que los OAA's puedan constituirse bajo la forma jurídica de sociedades, ya que estas tanto en el ámbito civil ${ }^{54}$ como en el mercantil ${ }^{55}$ se diferencian de las asociaciones y fundaciones en que su fin primordial es el ánimo de lucro ${ }^{56}$. En definitiva, los OAA's para cumplir con las exigencias propuestas por la LAI y por la normativa de la comunidad autónoma deberán constituirse como asociaciones o fundaciones ${ }^{57}$.

49 Para más información sobre la evolución de la legislación relativa a la regulación de los OAA’s en la Comunidad Autónoma de Madrid Vid. Preámbulo del Decreto 62/2003, de 8 de mayo, sobre acreditación, funcionamiento y control de las Entidades Colaboradoras de Adopción Internacional.

${ }^{50}$ Decreto 62/2003, de 8 de mayo, sobre acreditación, funcionamiento y control de las Entidades Colaboradoras de Adopción Internacional. BOCM núm. 115, de 16 de mayo de 2003, p. 9 a 18. [Web en línea], [fecha de consulta: 20 mayo 2016], Disponible en: <http://www.bocm.es/boletin/CM_Boletin_BOCM/20030516_B/11500.PDF>.

51 Orden de la Consejería de Asuntos Sociales, por la que se desarrolla el Decreto 62/2003, de 8 de mayo, del Consejo de Gobierno de la Comunidad de Madrid, sobre acreditación, funcionamiento y control de las Entidades Colaboradoras de Adopción Internacional, y se establece el modelo oficial de contrato de mediación en Adopción Internacional. BOCM núm.133, de 6 de junio de 2013, p. 11 a 18. [Web en línea], [fecha de consulta: 20 mayo 2016], Disponible en: < http://www.bocm.es/boletin/ CM_Boletin_BOCM/2013/06/06/13300.PDF>.

$\overline{52}$ Artículo 6.6 LAI: En las adopciones internacionales nunca podrán producirse beneficios financieros distintos de aquellos que fueran precisos para cubrir estrictamente los gastos necesarios de la intermediación ya probados por la Administración General del Estado y por la Entidades Públicas.

53 M. A. Calzadilla Medina, Op. Cit, p. 170

54 Artículo 1665 CC: La sociedad es un contrato por el cual dos o más personas se obligan a poner en común dinero, bienes o industria, con ánimo de partir entre sí las ganancias.

55 Artículo 116 CCom: El contrato de compañia, por el cual dos o más personas se obligan a poner en fondo común bienes, industria o alguna de estas cosas para obtener lucro, será mercantil, cualquiera que fuese su clase, siempre que se haya constituido con arreglo a las disposiciones de este Código. [...]

${ }^{56}$ M. A. Calzadilla Medina, Op. Cit, p. 170, Citando a P. Contreras: Ánimo de lucro: <intención de obtener un beneficio económico, tanto si se trata de un lucro directo que ingrese en el patrimonio social y que posteriormente se reparta entre los socios, como si lo que se pretende es conseguir un lucro indirecto, esto es, un ahorro para los socios debido a la prestación por la sociedad a estos de determinados servicios $>$.

57 Para más información Vid. M. A. Calzadilla Medina, Op. Cit, p. 169 y ss. 
En segundo lugar, parece interesante ver como el principio de prohibición de ánimo de lucro no queda desvirtuado cuando se afirma que los servicios de mediación que prestan los OAA's no son gratuitos. Existen una serie de trámites que realizan los OAA's en su labor de intermediación que suponen un coste, y que deben serle abonados por parte de los solicitantes, no obstante lo que se prohíbe es que el OAA se enriquezca mediante el ejercicio de sus actividades (Art. 6.6 LAI). El límite entre cobrar por los servicios prestados y enriquecerse por parte del OAA es difuso, sobre todo si consideramos que existen diferentes precios en los OAA's para los mismos servicios en una misma Comunidad Autónoma, la cual además ha autorizado las tarifas; es el caso de Cataluña, donde, además, se establece que el excedente de ingresos que se pudiera producir en los OAA's deberá ir destinado a una serie de programas determi$\operatorname{nados}^{58}$. En este último caso, estamos de acuerdo con M. A. Calzadilla Medina en que lo lógico sería devolver el excedente a las familias, para realmente asegurar que no existe ánimo de lucro en el OAA. Como vemos, el límite entre el cumplimiento y el incumplimiento de la prohibición del ánimo de lucro que se impone a los OAA's es difuso, por lo que en todo caso se alienta a los usuarios de los OAA's a que comuniquen a la autoridad correspondiente cualquier irregularidad que observen en los cobros exigidos por parte del OAA.

Por último, cabe hacer referencia a los esfuerzos de la Conferencia de la Haya para combatir el ánimo de lucro de los OAA's y su extralimitación en el cobro de honorarios a los solicitantes de adopción internacional, de este modo encontramos en la Guía de Buenas Prácticas nº 2 una serie de prácticas propuestas presididas por el principio: "mientras más dinero haya involucrado, menos probable es que se respeten las garantías de adoptabilidad" 59 .

Los OAA's deben hallarse inscritos en el registro correspondiente. Los OAA's pueden hallarse inscritas en dos registros diferentes sin que ello suponga problema alguno ${ }^{60}$. En este sentido, mientras que la inscripción registral de los estatutos o de la escritura fundacional en el registro correspondiente determina la adquisición de la personalidad jurídica, la inscripción en el registro público nacional creado específicamente para la inscripción de los OAA's da fe de los OAA's que han sido acreditados para realizar sus actividades de mediación. Cabe comentar que el registro nacional comentado ha sido introducido recientemente por la Ley 26/2005, lo que sin duda refuerza la seguridad jurídica de los usuarios de los mismos, ya que puede darse el caso de OAA's cuya acreditación ha sido revocada por la entidad pública competente pero que sin embargo siguen operando en el tráfico jurídico.

- Los OAA's deben tener como finalidad en sus estatutos la protección de menores.

- Los OAA's deben disponer de los medios materiales y equipos pluridisciplinares necesarios para el desarrollo de las funciones encomendadas.

- Los OAA's deben estar dirigidos y administrados por personas cualificadas por su integridad moral, por su formación y por su experiencia en el ámbito de la adopción internacional.

38. En segundo lugar, el Decreto 62/2003 lo que hace por su parte es concretar las exigencias del artículo 7 de la LAI en su artículo 6 desglosando los requisitos exigidos en Condiciones objetivas de la entidad solicitante, Medios humanos, materiales y técnicos, y Prescripciones técnicas, y especificando, por ejemplo y entre otras cuestiones, el número de profesionales y los estudios con los que deberán contar los miembros de su equipo multidisciplinar (Art. 6.8 Decreto 62/2003).

La entidad encargada de valorar si el OAA cumple los requisitos expuestos, y por consiguiente proceder a su acreditación, es la Administración General del Estado previo informe de la Entidad Pública en cuyo territorio tengan su sede, de acuerdo con el artículo 7.2 LAI. De acuerdo con lo anterior, en la Comunidad de Madrid la Entidad Pública competente para expedir el informe previo es la Dirección General de Familia y el Menor, adscrita a la Consejería de Políticas Sociales y Familia. Por su parte, el artículo 7.7 LAI establece que la Administración General del Estado también será competente para sus-

58 M. A. Calzadilla Medina, Op. Cit, p. 176

59 HCCH (Hague Conference on Private International Law), Acreditación y organismos acreditados para la adopción, Op. Cit., p. 74 y ss.

60 Ibídem. p. 177. 
pender o retirar, a iniciativa propia o a propuesta de las Entidades Públicas en su ámbito territorial, mediante expediente contradictorio, la acreditación concedida a aquellos organismos que dejen de cumplir las condiciones que motivaron su concesión o que infrinjan en su actuación el ordenamiento jurídico. La suspensión o retirada de la acreditación podrá tener carácter general, afectando a todos los países para los que estuviera autorizado, o podrá afectar a un país en concreto. En concreto en la Comunidad de Madrid, habrá de estar a los casos contemplados en el artículo 14 del Decreto 62/2003 relativos a la revocación de la acreditación.

39. Después de todo lo anterior cabe matizar que, a pesar de que un OAA cumpla todos los requisitos expuestos tanto en la LAI, como en la normativa específica de la comunidad autónoma, no tiene asegurada su acreditación en la comunidad autónoma. Esto se debe a que algunas comunidades autónomas han establecido el concurso público como mecanismo para conceder las acreditaciones y otras lo establecen como mecanismo excepcional, dependerá del número de solicitudes que se hayan tramitado con el concreto país extranjero al aumentar o disminuir el número de OAA's. De esta manera, lo que se consigue es que se acredite a los OAA's necesarios y a los mejor preparados para cubrir las necesidades de la comunidad autónoma ${ }^{61}$. En concreto, el funcionamiento del procedimiento de acreditación en la Comunidad Autónoma de Madrid se establece en el artículo 8 del Decreto 62/2003 ${ }^{62}$. Es importante en este punto esclarecer que la acreditación de los OAA's se realiza en relación a un país extranjero concreto, es decir, que la acreditación se expide por parte de la entidad pública competente para que el OAA actúe como entidad mediadora en tramitaciones de expedientes para un país concreto, si el OAA deseara tramitar solicitudes de adopción internacional en más de un país extranjero deberá solicitar acreditaciones separadas para cada uno de esos países.

40. Por otro lado, para que un OAA pueda desarrollar sus funciones como entidad mediadora en procedimientos de adopción internacional, no es suficiente con que cuente con la acreditación concedida por la entidad pública competente de la comunidad autónoma, ya que muchos estados extranjeros de origen de los menores adoptandos exigen que los OAA's extranjeros (en nuestro caso los OOAA's españoles) obtengan en dichos Estados una acreditación para poder operar ${ }^{63}$.

\section{B) Funciones y actividades}

41. Ya hemos visto que las funciones que desarrollan los OAA's son actividades de intermediación en el procedimiento de adopción internacional, no obstante cabe profundizar en las actividades que se les atribuye tanto a nivel nacional (LAI), como a nivel autonómico (en nuestro caso en la Comunidad de Madrid mediante el Decreto 62/2003), aunque en primer lugar cabe mencionar que las funciones y actividades de las entidades públicas competentes vienen establecidas en el artículo 5 de la LAI.

42. Las funciones y actividades que la LAI prevé en su artículo 6.3 para las OAA's acreditadas son las siguientes

a) Información a los interesados en materia de adopción internacional.

b) Asesoramiento, formación y apoyo a las personas que se ofrecen para la adopción en el significado e implicaciones de la adopción, en los aspectos culturales relevantes y en los trámites que necesariamente deban realizar en España y en los países de origen de los menores.

61 M. A. Calzadilla Medina, Op. Cit, p. 174

62 El Art. 8 del Decreto 62/2003 establece que se procederá a la acreditación a través de un procedimiento selectivo publicado mediante Orden cuando se produzca alguna de las circunstancias previstas; como ejemplo tenemos la Orden 698/2008, de 11 de abril, de la Consejería de Familia y Asuntos Sociales, por la que se aprueban las bases reguladoras y la convocatoria de concurso selectivo para la acreditación de las Entidades Colaboradoras de Adopción Internacional (EE CC AA II) que van a desarrollar funciones de mediación en los procedimientos de adopción que se efectúan en la República Socialista de Vietnam. BOCM núm. 110, de 9 de mayo de 2008, p. 30 a 36. [Web en línea], [fecha de consulta: 20 mayo 2016]. Disponible en: < https://www.bocm.es/boletin/CM_Boletin_BOCM/20080509_B/11000.pdf $>$.

63 A. L. Calvo Caravaca/J. Carrascosa González, Capitulo XX Adopción Internacional, Op. Cit., p. 370. 
c) Intervención en la tramitación de expedientes de adopción ante las autoridades competentes, tanto españolas como extranjeras.

d) Intervención en la tramitación y realización de las gestiones correspondientes para el cumplimiento de las obligaciones postadoptivas establecidas para los adoptantes en la legislación de origen del menor adoptado, que les serán encomendadas en los términos fijados por la Entidad Pública española donde resida la familia que se ofrece para la adopción.

43. En segundo lugar, la normativa autonómica pertinente desarrolla las funciones establecidas por la LAI para los OAA's, en concreto para la Comunidad Autónoma de Madrid el Decreto 62/2003 establece en sus artículos 15 a 17 la relación de las funciones y actividades que deberán ofrecer los OAA's en la Comunidad de Madrid, y de esta forma las divide en Funciones y actividades previas (art. 15), Funciones y actividades durante la tramitación del expediente (art. 16) y Funciones y actividades posteriores (art. 17).

44. Es relevante en este punto, concretar que en ningún caso las entidades públicas podrán delegar la expedición del certificado de idoneidad ${ }^{64}$ de los solicitantes de adopción internacional a los OAA's. En este punto nos planteamos una simple pregunta ¿Por qué? Consideramos que la delegación de la realización del certificado de idoneidad a los OAA's puede ayudar a simplificar la tramitación del expediente de adopción internacional al ofrecer una serie de ventajas:

- se reduciría el tráfico de documentos entre las entidades públicas y los OAA’s.

- se podría alcanzar una especialización en los evaluadores ya que los mismos se dedicarían a la evaluación de los solicitantes para un determinado país de origen.

- la delegación de los certificados de idoneidad de los expedientes tramitados a través de OAA permitiría desahogar el volumen de solicitudes que reciben las entidades públicas.

- todo lo anterior repercutiría en un gran ahorro de tiempo en la tramitación del expediente.

45. Sin embargo, es cierto que todas las ventajas que ofrece la delegación de la realización certificado de idoneidad a los OAA's se podrían ver desvirtuadas si no existe un control sobre las mismas, ya que algunas de ellas podrían ver la oportunidad de conceder los certificados de idoneidad a solicitantes no idóneos sólo para poder tramitar la solicitud de adopción, lo que iría en contra del principio de interés de los menor que debe regir en todo el procedimiento de adopción internacional. Por ello se plantea que la delegación se podría llevar a cabo si se encomendara al organismo encargado de la supervisión del OAA la supervisión también de este aspecto.

46. Por otro lado, haciendo un ejercicio de Derecho comparado y acudiendo a la legislación estadounidense, encontramos que en la misma las entidades privadas son las encargadas de la realización del certificado de idoneidad de los solicitantes de adopción internacional ${ }^{65}$, por lo que vemos que esta opción ya se encuentra funcionando en otros países.

\section{C) Régimen de funcionamiento y obligaciones}

47. Las principales obligaciones a las que se encuentran sometidos los OAA's para realizar sus actividades son las siguientes:

\footnotetext{
${ }^{64}$ Artículo 5.d) LAI: La expedición, en todo caso, de los certificados de idoneidad, previa elaboración bien directamente o a través de instituciones o entidades debidamente autorizadas, del informe psicosocial de las personas que se ofrecen para la adopción, y, cuando lo exija el país de origen del adoptando, la expedición del compromiso de seguimiento. MSSSI, Gobierno de España, [Documento en línea], Op. Cit., p. 27

65 Bureau Of Consular Affairs-U.S. Department Of State, Working with an Adoption Service Provider, [Web en línea], [fecha de consulta: 20 mayo 2016], Disponible en: < http://travel.state.gov/content/adoptionsabroad/en/adoption-process/howto-adopt/working-with-an-adoption-service-provider.html>
} 
- Conocer y respetar en el desarrollo de sus funciones y actividades la legislación internacional, nacional y autonómica, así como la legislación del país extranjero de origen de los menores.

- Conocer y respetar en el desarrollo de sus funciones y actividades los principios generales que rigen el procedimiento de adopción internacional, teniendo especial consideración al principio de interés superior del menor.

- Tramitar exclusivamente los expedientes que cuenten con el preceptivo certificado de idoneidad expedido por la entidad pública competente.

- Conocer y respetar lo dispuesto en la Ley Orgánica 15/1999, de 13 de diciembre, de protección de datos de carácter personal ${ }^{66}$, en cuanto a la utilización y cesión de datos de los usuarios de sus servicios.

- Contar con representación en el país de recepción de menores y en el país de origen.

- Respetar las limitaciones en la tramitación de expedientes de adopción internacional, conforme a las cuales un solicitante de adopción internacional no podrá tramitar el mismo expediente a través de varias vías, esto es a través de entidad pública y OAA, o a través de dos OAA's diferentes; tampoco es posible tramitar al mismo tiempo expedientes para varios países diferentes. No obstante, cuando el país paralice los trámites de todos los expedientes de adopción internacional ya iniciados, sin que pueda preverse una continuación de estos en un plazo próximo, la entidad pública competente, podrá autorizar la tramitación de un segundo expediente en un país distinto, y si posteriormente, el país levantase dicha paralización, las personas solicitantes deberán optar por un expediente y desistir del otro. En general, la única tramitación de expedientes que podrán realizarse simultáneamente por parte de los solicitantes de adopción será un expediente de adopción nacional y otro de adopción internacional.

- Con carácter general los OAA's se encuentran acreditados para gestionar los expedientes de adopción internacional de los solicitantes que pertenezcan a su comunidad autónoma. No obstante, mediante el Acuerdo de Cooperación Interautónomico en materia de tramitación de solicitudes de adopción internacional a través de ECAI's, de 4 de noviembre de 1997, se acordó que los OAA's pudieran gestionar solicitudes de personas que fueran residentes en otras comunidades autónomas, siempre y cuando en sus comunidades autónomas de residencia no existiera ningún OAA habilitado para tramitar el expediente de adopción internacional con un país determinado ${ }^{67}$.

48. En concreto el régimen de funcionamiento y obligaciones de los OAA's de la Comunidad de Madrid se establece en los artículos 18 a 24 del Decreto 62/2003.

\section{D) Régimen económico y financiero}

49. En cuanto al régimen económico y financiero de los OAA's es importante tener en cuenta que no podrán imputarse a la misma gastos provenientes de la asociación o fundación que la sustenta, por lo que se deberá llevar una contabilidad separada y exclusiva en la que se registren los ingresos y los gastos derivados de las actividades y funciones que realiza el OAA en su papel como mediador en el procedimiento de adopción internacional.

50. El régimen económico y financiero de los OAA's se establece de manera pormenorizada en la legislación autonómica, en el caso de la Comunidad de Madrid la regulación de estas cuestiones se encuentra en los artículos 25 a 34 del Decreto 62/2003. A modo de ejemplo, este Decreto regula cuestiones como los ingresos recibidos de los solicitantes, los cuales no podrán ser superiores a los costes y

${ }^{66}$ Ley Orgánica 15/1999, de 13 de diciembre, de protección de datos de carácter personal. BOE núm. 298, de 13 de diciembre de 1999, p.43088 a 43099. [Web en línea], [fecha de consulta: 20 mayo 2016]. Disponible en: < https://www.boe.es/ buscar/doc.php?id=BOE-A-1999-23750>.

67 M. A. Calzadilla Medina, Op. Cit, p. 173; A. Cerqueiro Nuñez, Op. Cit., p.18; A. Berástegui Pedro-Viejo/B. Gómez Bengoechea/S. Adroher Biosca, Op. Cit., p. 48. 
gastos reales de la tramitación previstos en el proyecto presentado para la acreditación y justificados en las memorias anuales (Art. 25), la diferenciación entre gastos directos y gastos indirectos (Art. 27), la consideración de las donaciones humanitarias (Art. 28), el fraccionamiento de los pagos (Art. 30) o la publicidad de los costes (Art. 31).

\section{E) Supervisión y control}

51. La importancia de las actividades que desarrollan los OAA's en el procedimiento de adopción internacional hace indispensable que las mismas sean inspeccionadas y controladas, en este sentido el artículo 7.2 LAI establece que competerá a la Administración General del Estado el control y seguimiento de los OAA's respecto de las actividades de intermediación que vayan a desarrollar en el país de origen de los menores, y por su parte el apartado tercero del mismo artículo dispone que "El control, inspección y seguimiento de estos organismos respecto a las actividades que se vayan a desarrollar en el territorio de cada comunidad autónoma, corresponderá a la Entidad Pública competente en cada una de ellas, de acuerdo con las normativa autonómica aplicable. Las entidades públicas competentes procurarán la mayor homogeneidad posible en los requisitos básicos para la realización de esa actividad de control, inspección y seguimiento". Por último, cabe comentar que el artículo 7 estipula también en su apartado octavo que para el seguimiento y control de los OAA's se establecerá la correspondiente coordinación de la Administración General del Estado con las Entidades Públicas.

52. Siguiendo estas exigencia, las Comunidades Autónomas han establecido la supervisión de los OAA's por parte de los Servicios de Inspección de la entidad pública autonómica, en este sentido encontramos para Madrid el artículo 35 del Decreto 62/2003 en el que se designa al Instituto Madrileño del Menor y la Familia como principal entidad supervisora de los OAA's que desarrollan funciones en la Comunidad de Madrid. No obstante, debemos tener en cuenta que el Instituto Madrileño del Menor y la Familia creado por la Ley 2/1996, de 24 de junio, de creación del Organismo Autónomo Instituto Madrileño del Menor y la Familia ${ }^{68}$ fue suprimido por el art. 5.7 del Decreto $72 / 2015$, de 7 de julio, por el que se modifica la estructura orgánica de las Consejerías de la Comunidad de Madrid ${ }^{69}$, asumiendo sus competencias la Dirección General de Familia y el Menor, adscrita a la Consejería de Políticas Sociales y Familia ${ }^{70}$.

53. Además de la designación de la entidad pública competente en la Comunidad Autónoma encargada de la supervisión de los OAA's, los Decretos de las Comunidades Autónomas también precisan el régimen sancionador aplicable a los OAA's; en el caso de Madrid encontramos el régimen sancionador aplicable en el artículo 37 del Decreto 62/2003, el cual remite al régimen sancionador establecido en el Título IV de la Ley 6/1995, de 28 de marzo, de Garantías de los Derechos de la Infancia y la Adolescencia en la Comunidad de Madrid ${ }^{71}$, en el Capítulo IV de la Ley 11/2002, de 18 de diciembre, de Ordenación de la Actividad de los Centros y Servicios de Acción Social y de Mejora de la Calidad en la Prestación de Servicios Sociales en la Comunidad de Madrid ${ }^{72}$, y en el Decreto 245/2000, de 16

68 Ley 2/1996, de 24 de junio, de creación del Organismo Autónomo Instituto Madrileño del Menor y la Familia. BOCM núm. 156, de 2 de julio de 1996, p. 3 a 6. [Web en línea], [fecha de consulta: 20 mayo 2016]. Disponible en: < https://www. bocm.es/boletin/CM_Boletin_BOCM/19960702_B/15600.pdf>.

${ }^{69}$ Decreto $72 / 2015$, de 7 de julio, del Consejo de Gobierno, por el que se modifica la estructura orgánica de las Consejerías de la Comunidad de Madrid. BOCM núm. 160, de 8 de julio de 2015, p. 15 a 21. [Web en línea], [fecha de consulta: 20 mayo 2016]. Disponible en: < https://www.bocm.es/boletin/CM_Boletin_BOCM/2015/07/08/16000.PDF >. Corrección de errores: BOCM de 13 y 24 de julio de 2015.

70 Véase el Decreto 197/2015, de 4 de agosto, por el que se establece la estructura orgánica de de la Consejería de Políticas Sociales y Familia. BOCM 185, de 6 de agosto de 2015, p. 94 a 104. [Web en línea], [fecha de consulta: 20 mayo 2016]. Disponible en: < https://www.bocm.es/boletin/CM_Boletin_BOCM/2015/08/06/18500.PDF>. Corrección de errores: BOCM de 7 de agosto de 2015.

${ }^{71}$ Ley 6/1995, de 28 de marzo, de Garantías de los Derechos de la Infancia y la Adolescencia en la Comunidad de Madrid. BOE núm. 183, de 2 de agosto de 1995, p. 23670 a 23688. [Web en línea], [fecha de consulta: 6 de diciembre 2014]. Disponible en: < http://www.boe.es/boe/dias/1995/08/02/pdfs/A23670-23688.pdf>.

${ }^{72}$ Ley $11 / 2002$, de 18 de diciembre, de Ordenación de la Actividad de los Centros y Servicios de Acción Social y de Me- 
de noviembre, por el que se aprueba el Reglamento para el ejercicio de la Potestad Sancionadora por la Administración de la Comunidad de Madrid $^{73}$. También se prevén en la normativa autonómica cauces de información y comunicación con las autoridades y entidades competentes que se encuentren en el Estado extranjero de origen en el que los OAA's están autorizadas para desarrollar sus funciones en el procedimiento de adopción internacional, y también con los órganos competentes de otras Comunidades Autónomas en las que el OAA se encuentre igualmente acreditado, en concreto en la Comunidad de Madrid el Art. 35.2 del Decreto 62/2003 dispone que "Cuando la misma Entidad Colaboradora sea acreditada también en otra u otras Comunidades Autónomas, el Instituto Madrileño del Menor y la Familia establecerá la oportuna coordinación con sus órganos competentes a efectos de control").

54. Es interesante en este punto estudiar qué ocurre cuando un organismo acreditado en varias Comunidades Autónomas pierde la acreditación en alguna de ellas, ya que vimos que la Administración General del Estado por iniciativa propia o a propuesta de las Entidades Públicas en su ámbito territorial podrá suspender o retirar la acreditación concedida a los organismos, pudiendo tener dicha retirada carácter general, afectando así a todos los países para los que estuviera autorizado, o sólo para algún país concreto, y por otra parte que ocurre cuando es el país de origen de los menores el que desacredita la actividad de la ECAI en el país, ya que como vimos las ECAI's deben contar con una doble acreditación (en el país de recepción de menores y en el país de origen) para poder desarrollar su función de mediación en el procedimiento de adopción internacional ${ }^{74}$.

55. Para resolver la primera cuestión, debemos recordar dos aspectos que ya hemos visto. En primer lugar que, a pesar de la última reforma de la LAI en la que se otorgan a la Administración General del Estado competencias para intentar conseguir una mayor unificación, la regulación de las actividades de los OAA's sigue siendo fundamentalmente autonómica, y por tanto rige el principio de territorialidad, y en segundo lugar, derivado de lo anterior, debemos tener en cuenta que cada Comunidad Autónoma ha establecido su proceso y sus requisitos de acreditación de OAA's en su territorio. Por lo anterior, podemos establecer que la desacreditación de un OAA en una Comunidad Autónoma no va a impedir que el mismo OAA continúe con sus actividades de mediación en otra Comunidad Autónoma en la que mantenga la acreditación. No obstante, esta situación hace que la Comunidad Autónoma en la que el OAA continúa acreditada para prestar servicios supervise de manera más exhaustiva la actuación de dicho organismo. Por otro lado, es importante considerar también los efectos que esta desacreditación del OAA supone para las relaciones de la misma con el Estado de origen con el que desarrolla sus servicios de mediación. Cuando se produce esta situación, los países de origen no entienden por qué deben dejar de mantener el contacto con un OAA con el que hasta ese momento estaban tramitando las solicitudes de adopción, y que además sigue acreditado en su país. En definitiva, la desacreditación de un OAA genera desconfianza tanto a nivel nacional entre las autoridades públicas competentes de las Comunidades Autónomas, como a nivel internacional con los países de origen de los menores, donde se han dado casos en los que las tramitaciones se suspendieron hasta que la situación se hubo aclarado.

56. En la resolución de la segunda cuestión planteada, debemos recordar la necesidad de que los OAA's obtengan la doble acreditación que hemos comentado anteriormente para poder actuar como mediadoras. Para conocer las consecuencias que la retirada de la acreditación del OAA en el país de origen de los menores tiene para el organismo, habrá que estar a lo dispuesto en la legislación del Estado de origen, considerándose que en general se producirá la paralización en la tramitación de los expedientes que

jora de la Calidad en la Prestación de Servicios Sociales en la Comunidad de Madrid. BOCM núm. 304, de 23 de diciembre de 2002, p. 3 a 11. [Web en línea], [fecha de consulta: 6 de diciembre 2014]. Disponible en: < http://www.bocm.es/boletin/ CM_Boletin_BOCM/20021223_B/30400.PDF>.

73 Decreto $245 / 2000$, de $1 \overline{6}$ de noviembre, por el que se aprueba el Reglamento para el ejercicio de la Potestad Sancionadora por la Administración de la Comunidad de Madrid. BOCM núm. 279, de 23 de noviembre de 2000, p. 10 a 14. [Web en línea], [fecha de consulta: 6 de diciembre 2014]. Disponible en: < http://www.bocm.es/boletin/CM_Boletin_ BOCM/20001123_B/27900.PDF>.

74 M. A. Calzadilla Medina, Op. Cit., p.185 y ss. 
estuviese gestionando el OAA sin que pueda hacerse nada para evitarlo. Esta suspensión en las tramitaciones acarreará consigo que los solicitantes de adopción internacional tengan que buscar otro mediador para la tramitación del expediente de adopción, y que por su parte el OAA devuelva a dichos solicitantes las cantidades proporcionales que los mismos habían aportado para hacer frente a los gastos derivados de la tramitación del expediente de adopción internacional, así como abonarles las cantidades que se determinen si el OAA ha incurrido en responsabilidad. En este punto, cabe plantearnos qué pasaría si el OAA al que el país de origen ha retirado la acreditación estuviera acreditado en alguna otra Comunidad Autónoma. En esta situación, habrá de entenderse que la retirada de la acreditación en el país de origen afecta a la actuación del OAA en todas las Comunidades Autónomas en las que se encuentre acreditada, es decir, que el organismo en cuestión no podrá tramitar expedientes de adopción internacional con el país de origen que le ha revocado la acreditación en ninguna de las Comunidades Autónomas en las que se encuentre acreditado. Esta situación conlleva al final a la retirada de la acreditación igualmente por parte de las entidades públicas competentes de las Comunidades Autónomas en las que se encuentra el OAA, así como a una inspección por parte también de la entidad pública competente para investigar los motivos que han llevado a la retirada de la acreditación por parte del país de origen.

57. Otros de los mecanismos que se ofrecen para el control y supervisión de los OAA's son, la creación de un registro público nacional específico de los OAA's (Art. 7.2 LAI), un control sobre el número de OAA's en el caso de que el país extranjero de origen fije un límite en el número de los mismos (Art. 7.5 LAI), un control sobre el número de expedientes a tramitar con cada país y la distribución de ese número máximo entre comunidades autónomas y organismos acreditados (Art. 4.5 LAI), y por último, la creación de Registros de Reclamaciones e Incidencias formuladas por los usuarios de los OAA's contra los mismos (Art. 8.3 LAI), en la Comunidad de Madrid se crea este Registro de reclamaciones en virtud del artículo 39 del Decreto 62/2003.

58. Atendiendo a todo lo anterior, podemos observar que en nuestro país la supervisión e inspección de los OAA's es una actividad que se encuentra sometida al principio de territorialidad, por lo que cada Comunidad Autónoma encarga esta función a una entidad propia, la cual suele ser la entidad encargada de expedir el informe previo para la acreditación del organismo para la adopción internacional, produciéndose así un control muy dividido a pesar de la existencia de mecanismos de comunicación entre Comunidades Autónomas. Y aunque si bien es cierto que la LAI ha introducido la supervisión de la Administración General del Estado sobre las actividades que los organismos vayan a desarrollar en el país de origen de los menores, la regulación y control de las actividades de los OAA's se puede seguir considerando eminentemente autonómica.

Desde nuestro punto de vista, esta gestión de la calidad de los OAA's es acertada, ya que nadie mejor que la entidad pública de la Comunidad Autónoma conoce la legislación aplicable y los OAA's que actúan en su territorio. No obstante, creemos que sería acertado crear un organismo especializado de control a nivel nacional que supervisase la actuación de los OAA's, sobre todo las actividades de aquellas que se encuentran acreditadas en más de una Comunidad Autónoma, ya que en casos como los que hemos visto de desacreditación de un OAA en una Comunidad Autónoma que no afecta a las demás en las que se halle habilitada, o en los casos de desacreditación por parte del país de origen, se crea un ambiente de desconfianza para los solicitantes, para las propias entidades e incluso para los países de origen de los menores que sin duda afecta negativamente a la tramitación de adopciones internacionales en España a través de los OAA's, que se podría paliar concentrando ciertas funciones de supervisión en determinados casos en un organismo estatal, o incluso mediante la publicación de directrices por parte del mismo. Este modelo se ha adoptado en los Países Bajos, donde la labor de inspección y supervisión del conjunto de entidades privadas que prestan servicios para la infancia la lleva a cabo la denominada "Inspección de Prestación de Ayuda y Protección a los Jóvenes", organismo perteneciente al Ministerio de Asuntos Sociales ${ }^{75}$. En otro países como en Reino Unido, se han establecido directrices internas a nivel nacional para unificar la labor de seguimiento y control de los OAA's mediante un documento

75 M. A. Calzadilla Medina, Op. Cit., p.183 
del Ministerio de Salud denominado "Inspección de agencias voluntarias de adopción. Parámetros y criterios" 76 .

\section{F) La relación jurídica entre los solicitantes de adopción internacional y el Organismo Acreditado para la Adopción Internacional}

59. Desde el momento en el que los solicitantes de adopción internacional acuerdan con una OAA la tramitación del expediente de adopción internacional a cambio de un precio podemos afirmar que entre las partes se establece una relación contractual; en este sentido encontramos el apartado primero del artículo 8 LAI: "Las personas que se ofrecen para la adopción podrán contratar los servicios de intermediación de cualquier organismo que se encuentre acreditado por la Administración General del Estado"; y en el apartado segundo: "El organismo y las personas que se ofrecen para la adopción formalizarán un contrato referido exclusivamente a las funciones de intermediación que aquella asume con respecto a la tramitación del ofrecimiento de adopción. El modelo básico de contrato ha de ser previamente homologado por la Administración General del Estado y las Entidades Públicas, en la forma que se determine reglamentariamente".

Se han discutido varios aspectos sobre esta relación contractual que se establece entre las personas que se ofrecen para la adopción internacional y el OAA, entre los que destacamos la categoría contractual en la que se encuadra el contrato de intermediación y el carácter público o privado del mismo.

60. En primer lugar, en cuanto a la categoría contractual en la que podríamos encuadrar el contrato, se plantean cuatro opciones. Se considera que el contrato de intermediación se puede encuadrar en el contrato de arrendamiento de servicios ${ }^{77}$, en el contrato de mediación ${ }^{78}$, en el contrato de mandato ${ }^{79}$, incluso se considera que ninguna de las formas contractuales citadas permiten englobar este tipo de contratos, estando por tanto ante una nueva figura y calificando el contrato como atípico por carecer de legislación específica ${ }^{80}$.

Atendiendo a la jurisprudencia y atendiendo a las características propias de cada uno de los contratos planteados, consideramos que el contrato de intermediación suscrito entre el OAA y los adoptantes se encuadra en la figura del contrato de arrendamiento de servicios. El contrato de arrendamiento de servicios se encuentra regulado en el artículo $1544 \mathrm{CC}$, el cual dispone que "en el arrendamiento de obras o servicios, una de las partes se obliga a ejecutar una obra o a prestar a la otra un servicio por precio cierto". El contrato de arrendamiento de servicios se caracteriza por ser un contrato consensual al perfeccionarse por el mero consentimiento de las partes, bilateral al originar obligaciones recíprocas entre las partes (prestación del servicio y del precio acordados), y como se desprende de lo anterior, es oneroso y conmutativo al prestarse un servicio a cambio de algo cierto; por último es importante tener en cuenta que para la formalización del contrato de arrendamiento de servicios no se exige ningún requisito de forma (Art. $1278 \mathrm{CC}^{81}$ ), y que el contrato podrá tener duración indefinida pero no será válido aquel que se establezca para toda la vida (Artículo $1583 \mathrm{CC}$ ) ${ }^{82}$.

76 Ibídem, p. 184.

77 Artículo 1544 CC: En el arrendamiento de obras o servicios, una de las partes se obliga a ejecutar una obra o a prestar a la otra un servicio por precio cierto.

78 Contrato atípico. No se encuentra regulado en el CC por lo que habrá que estar a lo establecido por las partes y en su defecto a las disposiciones generales sobre contratación establecidas en los Títulos I y II del Libro IV del CC, a los usos y costumbres, así como a las normas de los contratos con los que guarde afinidad. Jurisprudencialmente: STS 105/2013, Fundamento de Derecho Segundo.

79 Artículo 1709 CC: Por el contrato de mandato se obliga una persona a prestar algún servicio o hacer alguna cosa, por cuenta o encargo de otra.

80 M. A. Calzadilla Medina, Op. Cit., p.190

81 Artículo $1278 \mathrm{CC}$ : Los contratos serán obligatorios, cualquiera que sea la forma en que se hayan celebrado, siempre que en ellos concurran las condiciones esenciales para su validez.

82 M. A. Calzadilla Medina, Op. Cit., p.193 y 194; M. R. Díaz Romero, Tema 8 El contrato de depósito, mandato y arrendamiento de servicios, en R. Aranda Rodríguez/M. R. Díaz Romero/M. G. Rodríguez De Almeida/ M. I. Mondéjar Peña/M. 
61. En definitiva, el objeto del contrato de arrendamiento de servicios acoge las funciones de intermediación que realiza el OAA a favor de los adoptantes: prestación de un servicio, o en definitiva, desarrollo de una actividad, y recoge las obligaciones y derechos de cada una de las partes de la relación jurídica, las cuales también se identifican con las propias de la relación entre el OAA y los adoptantes; en ese sentido, el arrendatario de servicios, es decir el OAA, deberá prestar un servicio en cumplimiento de una obligación de hacer, y estará obligado a actuar según la diligencia y pericia requerida por la actividad a desarrollar o la lex artis ad hoc. Por otro lado, el arrendador de servicios, en nuestro caso los adoptantes, deberá pagar la contraprestación pactada, que será, de acuerdo a lo dispuesto en el artículo 1544 CC, el precio cierto ${ }^{83}$.

Si bien es cierto que hay autores que han defendido que el contrato de intermediación quedaría encuadrado en la figura del contrato de mandato ${ }^{84}$, varias sentencias califican el contrato entre las partes como arrendamiento de servicios (SAP Barcelona 7 de octubre de 2002; SAP Madrid 11 de julio de 2007; SAP Murcia 15 de julio de 2010; SAP Islas Baleares 18 de abril de 2012), e incluso desde la Comunidad de Madrid los abogados del departamento de adopción de la Consejería de Políticas Sociales y Familia aseguran que ellos consideran el contrato de intermediación como un contrato de arrendamiento de servicios ${ }^{85}$, siendo tal servicio la intermediación o mediación que presta el OAA a los adoptantes en la gestión del proceso de adopción internacional.

62. En cualquier caso, e independientemente de la figura jurídica en la que encuadremos el contrato de intermediación entre el OAA y los adoptantes, lo relevante a tener en cuenta en la relación jurídica que se constituye entre las partes a partir del contrato de intermediación de adopción internacional es que estamos ante un contrato de medios y no de resultado, por ello el arrendatario (OAA) no está obligado a garantizar un resultado, sino que deberá hacer lo posible con la diligencia debida para conseguir tal resultado, e independiente de si consigue o no el resultado, en nuestro caso la constitución de la adopción internacional, el arrendador (adoptante) deberá pagar el precio ${ }^{86}$ (SAP Barcelona 7 de octubre de 2002 ${ }^{87}$; SAP Madrid 11 de julio de 200788; SAP Murcia 15 de julio de $2010^{89}$; SAP Islas Baleares 18 de abril de $2012^{90}$ ). En este sentido, la no constitución de la adopción no puede considerarse en todos los casos un incumplimiento contractual por parte del OAA, siempre y cuando esta haya empleado la diligencia debida en la realización de sus funciones como ya hemos comentado, ya que no debemos olvidar que la constitución de la adopción queda en manos de un juez que podrá denegar dicha constitución por considerar que concurre falta de idoneidad de los adoptantes, que debe concurrir una propuesta previa de adopción acordada por el país de origen y por el de recepción del menor que puede no ser favorable, o por la declaración de falta de idoneidad de los adoptantes en la Fase Administrativa de Instrucción. En

P. Pérez Álvarez, Guía de Derecho Civil. Teoría y Práctica. Teoría general del contrato y contratos en particular. Contratos, Tomo III, Navarra, Thomson Reuters, 2013, p.383 y ss.

83 M. R. Díaz Romero, Tema 8 El contrato de depósito, mandato y arrendamiento de servicios, Op. Cit., p. 383 y ss.

84 Vid. M. A. Calzadilla Medina, Op. Cit., p. 195 y ss.

85 Consulta telefónica realizada al equipo de abogados del IMMF en Enero de 2015.

86 M. A. Calzadilla Medina, Op. Cit., p. 193 y 194; M. R. Díaz Romero, Op. Cit. p. 383; A. L. Calvo Caravaca/J. CaRRascosa GonzÁlez, Capítulo XX Adopción Internacional, Op. Cit., p. 370.

87 SAP Barcelona 7 de octubre de 2002, JUR/2003/21860. Fundamento de Derecho Tercero.

88 SAP Madrid 11 de julio de 2007, AC/2007/1749.Fundamento de Derecho Segundo: [...] Es contrato de medios y no de resultado, que se perfecciona por el mero consentimiento según las normas generales del art. 1261 CC (LEG 1889, 27), sin que la percepción del precio de la intermediación se anude o pueda anudarse a la feliz obtención del resultado, y eso es así porque en ese ámbito la obtención del resultado no depende de la gestión de los mediadores. El resultado final depende de la decisión del Tribunal nacional del adoptando, por definición ajeno a los esfuerzos de intermediario, y tras la celebración de un proceso en el que deben evaluarse todos los aspectos de la situación, desde todos los puntos de vista, y con una norma de valoración especifica; el beneficio del menor adoptando.[...]

89 SAP Murcia 15 de julio de 2010, JUR/2010/296248. Fundamento de Derecho Segundo.

90 SAP Islas Baleares 18 de abril de 2012, JUR/2012/163300. Fundamento de Derecho Segundo: El contrato celebrado entre las partes es un arrendamiento de servicios en el que la entidad colaboradora en la adopción internacional asume una obligación de medios y no de resultado. Ello quiere decir que, evidentemente, la ECAI no puede comprometerse a que su intermediación culmine con la adopción, por parte de sus clientes, del niño o niña, pero sí a poner todos los medios a su alcance, en los términos pactados en el contrato, para que dicho resultado sea posible.[...] 
definitiva, es importante tener en cuenta que el incumplimiento por parte del OAA se produce cuando no realiza sus tareas de intermediación de forma diligente, ya que hay muchos organismos que participan en el procedimiento de adopción y que pueden denegar su constitución o su tramitación sin que ello signifique que el OAA ha ejercido sus funciones de manera negligente, de esta manera vemos con más claridad porque afirmamos que a efectos prácticos es más importante tener en cuenta que estamos ante un contrato de medios y no de resultado, que encuadrar el contrato de intermediación entre el OAA y adoptantes en una figura contractual concreta.

63. En segundo lugar, se ha discutido sobre la naturaleza pública o privada del contrato de intermediación celebrado entre los solicitantes de adopción internacional y el OAA. A pesar de que los OAA's están sometidas a un gran control por parte de la Administración Pública, como la necesidad de ser acreditadas por la Administración General del Estado, previo informe de la Entidad Pública competente, para el ejercicio de sus actividades, la supervisión y control que llevan a cabo estas sobre aquellas, o la utilización de un modelo de contrato homologado que desarrollaremos más adelante, no podemos determinar que estemos ante Derecho Público. Tanto el OAA como los adoptantes son entes privados, y a pesar de que el OAA esté sometido a altas exigencias por parte de la Administración Pública sigue manteniendo su carácter de empresa privada que ofrece un servicio a las personas que lo demanden. Por todo lo anterior, concluimos que la relación contractual que se establece entre el OAA y los adoptantes queda al amparo del Derecho Privado y de la jurisdicción Civil en el caso de que surjan discrepancias en la prestación de servicios relativos a los derechos y obligaciones de las partes en la relación contractual.

64. Por último, es importante hacer referencia a lo dispuesto en el artículo 8.2 LAI sobre la necesidad de homologación del modelo básico de contrato de intermediación entre los OAA's y los adoptantes por la Administración General del Estado y la Entidad Competente, que ya hemos adelantado anteriormente. Cumpliendo con lo dispuesto, cada Comunidad Autónoma ha homologado el modelo de contrato básico al que deberán atenerse OAA's y adoptantes a la hora de formalizar su relación jurídica. La autoridad competente para la homologación del modelo en la Comunidad de Madrid es la Consejería de Asuntos Sociales, y el modelo homologado se encuentra en la Orden 526/2013, de 20 de mayo, de la Consejería de Asuntos Sociales, por la que se desarrolla el Decreto 62/2003, de 8 de mayo, del Consejo de Gobierno de la Comunidad de Madrid, sobre acreditación, funcionamiento y control de las Entidades Colaboradoras de Adopción Internacional, y se establece el modelo oficial de contrato de mediación de Adopción Internacional ${ }^{11}$. Este modelo homologado es el que debe utilizarse en todo caso en la relación de intermediación entre los OAA's acreditados en la Comunidad de Madrid y los adoptantes que acudan a los mismos para la tramitación de la adopción internacional.

De acuerdo a lo dispuesto en el artículo 2 de la Orden 526/2013, estamos ante un modelo cerrado en todas sus estipulaciones que solamente podrá ser modificado en el caso de que las peculiaridades específicas de la situación o del país así lo exijan; la incorporación de las modificaciones pertinentes en el modelo homologado y obligatorio deberán justificarse y el mismo será remitido antes de su firma a la Dirección General de Familia y el Menor, la cual asume las competencias del antiguo Instituto Madrileño del Menor y la Familia, para su visado, y en su caso, para su autorización. Dicha autorización para la modificación del contrato homologado responderá a un caso concreto y puntual que resultará debidamente analizado, por lo que el contrato resultante tras las modificaciones introducidas y autorizadas no se convertirá, en ningún caso, en un nuevo modelo de contrato para el OAA, es decir, el contrato con las debidas modificaciones resultará válido para la situación y el proceso concreto de adopción para el que las mismas fueron introducidas, no pudiéndose utilizar para sucesivos procesos de adopción ajenos a la circunstancia que motivó la modificación del modelo de contrato básico homologado; en definitiva, para nuevas situaciones deberá adoptarse el modelo de contrato básico homologado por la Orden 562/2013 y si procediera volver a intro-

91 Orden 526/2013, de 20 de mayo, de la Consejería de Asuntos Sociales, por la que se desarrolla el Decreto 62/2003, de 8 de mayo, del Consejo de Gobierno de la Comunidad de Madrid, sobre acreditación, funcionamiento y control de las Entidades Colaboradoras de Adopción Internacional, y se establece el modelo oficial de contrato de mediación de Adopción Internacional. BOCM núm. 133, de 6 de junio de 2003, p. 11 a 18. [Web en línea], [fecha de consulta: 6 de diciembre 2014]. Disponible en: < http://www.bocm.es/boletin/CM_Boletin_BOCM/2013/06/06/13300.PDF>. 
ducir modificaciones en el modelo básico, estas deberán volver a ser justificadas y aprobadas para ese caso concreto, y de nuevo, el modelo resultante solamente será válido para el caso concreto.

En otras Comunidades Autónomas las Autoridades Competentes han hecho lo propio, y han publicado el modelo oficial aprobado para los servicios de intermediación que presten los OAA's acreditadas en su territorio. Encontramos, entre otros, el modelo de contrato aprobado por Galicia ${ }^{92}$, en el que se anexa una lista de conceptos directos e indirectos para fijar el precio de la adopción, los cuales deberán estar debidamente justificados. A día de hoy en Galicia se está llevando a cabo el proceso de cambio para instaurar el modelo básico homologado en todos los servicios de intermediación que ofrecen los OAA's en el territorio, no obstante, todavía hay OAA's que siguen funcionando con modelos propios anteriores a la entrada en vigor de la Orden de 21 de marzo de 2012.

La homologación de un modelo básico de contrato de intermediación en virtud del artículo 8.2 LAI aporta seguridad jurídica a las relaciones contractuales entre los OAA's y las personas que se ofrecen para la adopción internacional. Las dificultades que se presentan a la hora de encuadrar la relación jurídica que se establece entre los OAA's y los adoptantes, y la obligación de ausencia de ánimo de lucro que se exige a los OAA's al realizar los trámites procedentes en el proceso de adopción internacional, son las dos principales exigencias que se intentan asegurar con la publicación de los modelos homologados. Acotar lo máximo posible los términos y obligaciones de cada una de las partes en esta compleja relación de intermediación ofrece información y seguridad a ambas partes sobre sus derechos y obligaciones, lo que se traduce, como ya hemos comentado, en un aumento de la seguridad jurídica del proceso de adopción internacional a través de los OAA's y en un mayor control por parte de la Administración Pública sobre las actividades de las mismas.

\section{Conclusiones sobre el proceso de adopción internacional en España y sobre la intervención de los Organismos Acreditados para la Adopción Internacional en la Fase Administrativa de Instrucción}

65. Observando todo lo expuesto en esta investigación, podemos realizar una serie de valoraciones en torno a las dos cuestiones planteadas como objeto de estudio. Por un lado, la primera cuestión planteada brevemente en esta investigación hace referencia al desarrollo del proceso de adopción internacional en nuestro país, y por otro lado, y como cuestión principal de la investigación encontramos la intervención de los Organismos Acreditados para la Adopción Internacional en la Fase Administrativa de Instrucción y la consecuente valoración de dicha intervención.

66. Tras el breve estudio del proceso de adopción internacional podemos afirmar, de acuerdo a lo anterior, que desde la perspectiva jurídica la configuración que se ha forjado en nuestro país de la institución jurídica de la adopción internacional, su regulación sus procedimientos y sus caracteres propios, ha hecho que la institución se presente como eficiente y eficaz para su fin, el cual es la protección de menores, que no pueden ser adoptados o acogidos en sus países de origen, mediante la búsqueda de una familia española para los mismos. No obstante, la investigación ha dejado patente que desde una perspectiva psicológica y social hay varios puntos que no se han tenido en cuenta y que hacen peligrar la eficacia de la institución, a saber la problemática psicológica particular que plantea la constitución de una adopción internacional, sobre todo en dos etapas del proceso de adopción internacional, nos referimos a la expedición del certificado de idoneidad y principalmente al proceso post-adoptivo que ha quedado relegado a un segundo plano en su visión psicológica y que sólo ha sido contemplado por la legislación debido a las exigencias de los países de origen de los menores que demandan la realización de una serie de controles legales para realizar un seguimiento del menor y su situación en el país de recepción pero que en ningún caso van directamente dirigidos a conseguir el vínculo de parentesco o integración familiar. Por todo lo anterior, la fase de post-adopción merece una revisión desde el ám-

92 Orden 21 de marzo de 2012 por la que se establece el modelo oficial de contrato de intermediación en adopción internacional para la Comunidad Autónoma de Galicia. DOG núm. 73, de 17 de abril de 2012, p. 13662 a 13676. [Web en línea], [fecha de consulta: 6 de diciembre 2014]. Disponible en: < http://www.xunta.es/dog/Publicados/2012/20120417/AnuncioCA05-110412-0003_es.html>. 
bito psicológico y jurídico, a pesar de que ya existen ciertas exigencias legales en este ámbito a nivel autonómico, sobre todo en el ámbito de las OAA's, podemos afirmar que las mismas son preceptos de interpretación vaga.

67. Terminada la evaluación del proceso de adopción internacional en España, el estudio de la intervención de los OAA's en la Fase Administrativa de Instrucción nos ha dejado otra serie de conclusiones interesantes sobre su funcionamiento. Sin duda, podemos afirmar que la delegación de ciertas funciones en estos organismos ha supuesto un avance y un ahorro de tiempo en la tramitación de los expedientes de adopción internacional, ya que antes de esta delegación nos encontrábamos ante una Administración Pública colapsada que preveía unas esperas de meses e incluso años para la expedición de dichos expedientes. Además, desde el punto de vista de los solicitantes de adopción internacional es interesante contar con dos vías entre las que elegir para la tramitación del expediente de adopción internacional, ya que podrán optar por la que más se ajuste a sus posibilidades, necesidades e intereses, o incluso recordamos que las adopciones para ciertos países solo se tramitan a través de estas entidades, por lo que de no existir las mismas los solicitantes de adopción internacional no podrían platearse adoptar a un menor de dichas naciones. Por otro lado, la exigencia de que los OAA's tengan que contar con una serie de profesionales con experiencia en el ámbito de las adopciones internacionales supone otro aspecto positivo, ya que estamos ante organismos especializados en la materia, y conscientes de la problemática particular que se desprende de la institución jurídica adoptiva.

Esos aspectos positivos que hemos comentado podrían aumentar si se produjera la delegación de la tramitación del certificado de idoneidad, siempre bajo fuertes controles de la Administración Pública para evitar situaciones fraudulentas en las que OAA's, cuya falta de ánimo de lucro fuera cuestionable, buscaran su propio beneficio al conceder dicho certificado a adoptantes no aptos para poder tramitar mayor número de adopciones internacionales. Mediante la delegación de la tramitación del certificado de idoneidad podríamos alcanzar una especialización y una profesionalización en la tramitación de los expedientes de adopción internacional, debido por un lado, a la exigencia que se impone a los OAA's de contar con profesionales formados y con amplia experiencia en el ámbito, y por otro lado debido al hecho de que sea una sola entidad la que gestione el completo expediente de adopción internacional. Además de la profesionalización y especialización conseguiríamos mayor ahorro de tiempo en la tramitación de los expedientes de adopción internacional y seguiríamos ayudando descongestionar el sistema público de tramitación de adopciones internacionales.

68. Por otro lado, no todo lo que se desprende de la investigación respecto a esta intervención de los OAA's en la Fase Administrativa de Instrucción es positivo, ya que encontramos un descontento general por parte de los adoptantes que han tramitado su expediente a través de estas entidades. La principal razón de este descontento gira en torno a la cuestión de si realmente los OAA's se fundan sin ánimo de lucro, ya que debemos tener presente que siguen siendo entidades privadas que ofrecen servicios a aquellos que los demanden. Las carencias de los OAA's que ha dejado patente la investigación se hacen visibles en relación contractual meramente profesional de los OAA's con los solicitantes de adopción internacional, en la desinformación de cuestiones relevantes como el número de informes post-adoptivos exigidos por el país de origen, o en los servicios post-adoptivos que se ofrecen. Todo ello hace que los solicitantes de adopción se planteen en muchos casos que el OAA está incumpliendo su contrato de intermediación, o simplemente que sólo busca el lucro propio.

Si bien es cierto que ya se encuentran vigentes varios instrumentos que intentan controlar la actuación de los OAA's en el tráfico jurídico, por ejemplo a través de la publicación de modelos básicos oficiales de intermediación, de acuerdo con lo que hemos venido comentando, el hecho de que sean entidades útiles pero que los solicitantes de adopción desconfíen en la mayoría de los casos de sus fines, hace que la intervención de los OAA's en la Fase Administrativa de Instrucción sea mejorable a través de una legislación más dura en el ámbito de la supervisión y control de las mismas, planteándose en este punto la creación de un órgano que controle la actuación de estas entidades a nivel nacional para conseguir una homogeneización en los criterios de lo que debe considerarse una prestación de servicios correcta por parte de los OAA's. 
69. En definitiva, el estudio nos deja con una sensación notablemente satisfactoria sobre el planteamiento de la institución jurídica de la adopción internacional en nuestro país y sobre la intervención de los OAA's en la Fase Administrativa de Instrucción del proceso de adopción internacional, no obstante queda mucho por hacer en el ámbito jurídico para que los factores psicológicos y sociales sean tenidos en cuenta a lo largo de todo el procedimiento, y para que el funcionamiento de los OAA's sea más eficiente y totalmente fiable para los solicitantes de adopción internacional. 